\title{
Geostationary Emission Explorer for Europe (G3E): mission concept and initial performance assessment
}

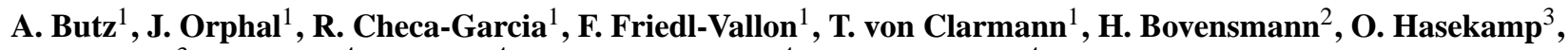 \\ J. Landgraf ${ }^{3}$, T. Knigge ${ }^{4}$, D. Weise ${ }^{4}$, O. Sqalli-Houssini ${ }^{4}$, and D. Kemper ${ }^{4}$ \\ ${ }^{1}$ IMK-ASF, Karlsruhe Institute of Technology (KIT), Leopoldshafen, Germany \\ ${ }^{2}$ Institute for Environmental Physics, University of Bremen, Bremen, Germany \\ ${ }^{3}$ Netherlands Institute for Space Research (SRON), Utrecht, the Netherlands \\ ${ }^{4}$ Airbus Defence and Space, Friedrichshafen, Germany \\ Correspondence to: A. Butz (andre.butz@kit.edu)
}

Received: 25 May 2015 - Published in Atmos. Meas. Tech. Discuss.: 8 July 2015

Revised: 23 October 2015 - Accepted: 2 November 2015 - Published: 10 November 2015

\begin{abstract}
The Geostationary Emission Explorer for Europe (G3E) is a concept for a geostationary satellite sounder that aims to constrain the sources and sinks of greenhouse gases carbon dioxide $\left(\mathrm{CO}_{2}\right)$ and methane $\left(\mathrm{CH}_{4}\right)$ for continental-scale regions. Its primary focus is on central $\mathrm{Eu}-$ rope. G3E carries a spectrometer system that collects sunlight backscattered from the Earth's surface and atmosphere in the near-infrared (NIR) and shortwave-infrared (SWIR) spectral range. Solar absorption spectra allow for spatiotemporally dense observations of the column-average concentrations of carbon dioxide $\left(\mathrm{XCO}_{2}\right)$, methane $\left(\mathrm{XCH}_{4}\right)$, and carbon monoxide (XCO). The mission concept in particular facilitates sampling of the diurnal variation with several measurements per day during summer.

Here, we present the mission concept and carry out an initial performance assessment of the retrieval capabilities. The radiometric performance of the 4 grating spectrometers is tuned to reconcile small ground-pixel sizes $(\sim 2 \mathrm{~km} \times 3 \mathrm{~km}$ at $50^{\circ}$ latitude) with short single-shot exposures $(\sim 2.9 \mathrm{~s})$ that allow for sampling continental regions such as central Europe within $2 \mathrm{~h}$ while providing a sufficient signal-to-noise ratio. The noise errors to be expected for $\mathrm{XCO}_{2}, \mathrm{XCH}_{4}$, and $\mathrm{XCO}$ are assessed through retrieval simulations for a European trial ensemble. Generally, single-shot precision for the targeted $\mathrm{XCO}_{2}$ and $\mathrm{XCH}_{4}$ is better than $0.5 \%$ with some exception for scenes with low infrared surface albedo observed under low sun conditions in winter. For XCO, precision is generally better than $10 \%$. Performance for aerosol and cirrus loaded atmospheres is assessed by mimicking G3E's slant
\end{abstract}

view on Europe for an ensemble of atmospheric scattering properties used previously for evaluating nadir-viewing lowEarth-orbit (LEO) satellites. While retrieval concepts developed for LEO configurations generally succeed in mitigating aerosol- and cirrus-induced retrieval errors for G3E's setup, residual errors are somewhat greater in geostationary orbit (GEO) than in LEO. G3E's deployment in the vicinity of the Meteosat Third Generation (MTG) satellites has the potential to make synergistic use of MTG's sounding capabilities e.g. with respect to characterization of aerosol and cloud properties or with respect to enhancing carbon monoxide retrievals by combining G3E's solar and MTG's thermal infrared spectra.

\section{Introduction}

Satellite remote sensing of man-made greenhouse gases has been suggested as a key enabling technology to facilitate policy-relevant monitoring of anthropogenic emissions and their interaction with the biogeochemical environment (e.g. Rayner and O'Brien, 2001; Ciais et al., 2014). Nadir-viewing satellite instruments such as the SCanning Imaging Absorption spectroMeter for Atmospheric CHartographY (SCIAMACHY) (Burrows et al., 1995; Bovensmann et al., 1999; Gottwald and Bovensmann, 2011), the Greenhouse Gases observing SATellite (GOSAT) (Kuze et al., 2009), and the Orbiting Carbon Observatory (OCO-2) (Crisp et al., 2004) demonstrate that the employed solar backscatter technique 
is able to deliver column-average concentrations of carbon dioxide $\left(\mathrm{XCO}_{2}\right)$ and methane $\left(\mathrm{XCH}_{4}\right)($ Frankenberg et al., 2005; Butz et al., 2011; Reuter et al., 2011; O’Dell et al., 2012) approaching the accuracy goal on the sub-percent level (e.g. Miller et al., 2007; Chevallier et al., 2007; Bergamaschi et al., 2007). The inferred concentration fields allow for detecting anthropogenic emissions over source regions such as urban centers and major fossil fuel production sites (e.g. Schneising et al., 2013; Kort et al., 2012; Reuter et al., 2014a; Kort et al., 2014). Likewise, SCIAMACHY- and GOSATderived $\mathrm{XCO}_{2}$ and $\mathrm{XCH}_{4}$ have been shown to successfully constrain patterns of biogeochemical sources and sinks either by feeding the satellite soundings into inverse models or by correlating observed concentration variability with climate variables (e.g. Bergamaschi et al., 2009; Guerlet et al., 2013a; Parazoo et al., 2013; Schneising et al., 2013; Ross et al., 2013; Basu et al., 2014; Reuter et al., 2014b).

The spatiotemporal resolution of current and upcoming satellite missions, however, is insufficient to reliably monitor point source emissions and to budget diffuse biogeochemical sources and sinks on regional scales $(100 \mathrm{~km} \times 100 \mathrm{~km})$ (Hungershoefer et al., 2010). Overcoming this limitation, Bovensmann et al. (2010) and Buchwitz et al. (2013) suggest the dedicated greenhouse gas mission CarbonSat that employs imaging capabilities to map the ground scene over a swath of a few hundred kilometers with about $2 \mathrm{~km} \times 2 \mathrm{~km}$ horizontal resolution. Together, the imaging capabilities and the high spatial resolution permit contrasting the foreground emission plumes to background concentrations by exploiting the spatiotemporal context of the scene. The Sentinel-5 Precursor (S5P) (Veefkind et al., 2012), due for launch in 2016, and the post-2020 Sentinel-5 (S5) (Ingmann et al., 2012) will target $\mathrm{XCH}_{4}$ only (e.g. Butz et al., 2012) with a viewing swath exceeding $1000 \mathrm{~km}$ but only moderate horizontal resolution of several tens $\mathrm{km}^{2}$. Velazco et al. (2011) examine a satellite constellation concept with five CarbonSatlike satellites. Such a constellation simultaneously allows for daily coverage and high horizontal resolution and thus, delivers improved capabilities to constrain anthropogenic emissions.

Common to the current and next-generation greenhouse gas sounders is their deployment in low-Earth orbit (LEO) which favors global coverage. However, depending on the exact orbit altitude and on the instruments' imaging capabilities, LEO restricts the number of revisits to a few per month per location for instruments with high spatial resolution such as CarbonSat. Daily revisits either require a constellation of satellites or come at the expense of only moderate spatial resolution such as for S5P and S5. In contrast, a geostationary orbit (GEO) promises much higher spatiotemporal data density, but only roughly one-third of the globe is observable, and high latitudes are viewed under large zenith angles. Bovensmann et al. (2002) suggest geostationary measurements of $\mathrm{CO}, \mathrm{CO}_{2}$ and $\mathrm{CH}_{4}$ and Bovensmann et al. (2004) provide an initial assessment of synergies for mea- suring $\mathrm{CH}_{4}$ and $\mathrm{CO}$ from geostationary orbit in the solar and thermal infrared. GEO-CARB (Polonsky et al., 2014) is a recently developed concept for a dedicated greenhouse gas sounder in geostationary orbit operating in a $2 \mathrm{~h}$ repeat cycle on $3 \mathrm{~km} \times 2.7 \mathrm{~km}$ horizontal resolution (at the sub-satellitepoint). Rayner et al. (2014) show that simulated GEO-CARB observations of $\mathrm{XCO}_{2}, \mathrm{XCH}_{4}$, and $\mathrm{XCO}$ over Asia can provide constraints on regional-scale emission patterns including individual point-source emissions. Several revisits per day in particular enables exploitation of diurnal concentration cycles e.g. specific to the build-up of anthropogenically emitted $\mathrm{CO}_{2}, \mathrm{CH}_{4}$, and $\mathrm{CO}$ in the urban boundary layer during the day (Wunch et al., 2009). Ciais et al. (2014) recommend investigating the potential of geostationary greenhouse gas sounders as one part of a policy-relevant carbon observing system together with improved sensors in LEO.

Here, we introduce the Geostationary Emission Explorer for Europe (G3E) with the goal of supporting a longterm European space-based emission monitoring strategy. G3E aims at quantifying the sources and sinks of $\mathrm{CO}_{2}$ and $\mathrm{CH}_{4}$ throughout central Europe. G3E targets emissions from point sources such as power plants as well as surface-atmosphere exchange due to biogeochemical processes. To this end, the grating spectrometer system collects absorption spectra of near-infrared (NIR) and shortwave-infrared (SWIR) sunlight backscattered by the Earth's surface and atmosphere. The instrument concept borrows design choices from its LEO precursors GOSAT, OCO-2, S5P, S5, and CarbonSat. Radiometric performance, however, is tuned to complete a scan of the central European continent such as shown in Fig. 1 within $2 \mathrm{~h}$ given a ground-pixel size of roughly $2 \mathrm{~km} \times 3 \mathrm{~km}$ (east-west $\times$ south-north at $50^{\circ}$ latitude and central European longitudes, $1.7 \mathrm{~km} \times 1.7 \mathrm{~km}$ at sub-satellite point). The spectrometers cover several molecular absorption bands between roughly 745 and $2400 \mathrm{~nm}$ enabling the retrieval of the targeted column-average greenhouse gas concentrations of $\mathrm{XCO}_{2}$ and $\mathrm{XCH}_{4}$, and in addition $\mathrm{XCO}$, the signal from plant chlorophyll fluorescence, particle scattering properties of the atmosphere, and concentrations of interfering molecular absorbers such as water vapor. The XCO measurements aim at better attributing $\mathrm{XCO}_{2}$ and $\mathrm{XCH}_{4}$ variability to combustion processes (e.g. Rayner et al., 2014) and at providing support for air-quality monitoring.

$\mathrm{G} 3 \mathrm{E}$ is to be deployed in a geostationary orbit at about $0^{\circ}$ longitude in the vicinity of the Meteosat Third Generation (MTG) satellites carrying in particular the Flexible Combined Imager (FCI), the Sentinel-4 (S4), and the Infrared Sounder (IRS) instruments. G3E's greenhouse gas sounding capabilities complement MTG's air-quality monitoring instruments that deliver concentrations of air pollutants such as ozone, nitrogen dioxide $\left(\mathrm{NO}_{2}\right), \mathrm{CO}$, and particulate matter. In the long term, these geostationary sounders aim at paving the way toward the routine use of observed gas concentrations in data assimilation systems for atmospheric monitor- 


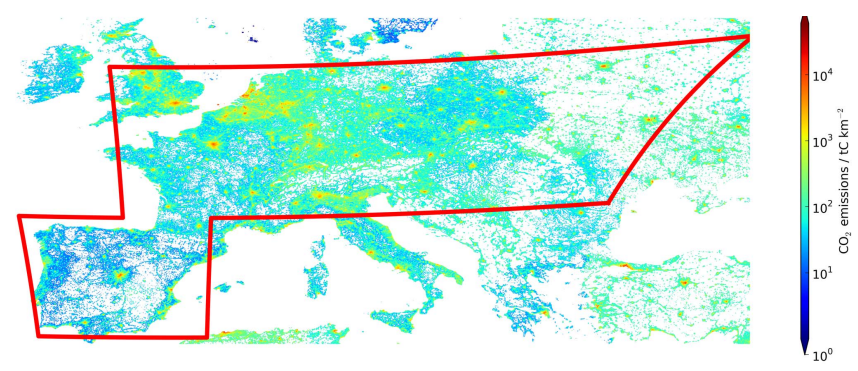

Figure 1. Illustrative G3E scan pattern to be covered from east to west within $2 \mathrm{~h}$ (red polygon). The assumed scan pattern would consist of a long east-to-west scan for central Europe and a second short scan for the Iberian peninsula. The background color code shows annual $\mathrm{CO}_{2}$ emissions for the year 2013 as extracted from the database built by Oda and Maksyutov (2011).

ing services such as developed within the European Copernicus programme (e.g. Inness et al., 2015).

While GEO-CARB (Polonsky et al., 2014; Rayner et al., 2014) demonstrates usefulness and capabilities of a geostationary greenhouse gas sounder, we address G3E-specific challenges which are the small ground-pixel area observed under small solid angles from GEO and a European focus region seen under slant viewing angles. The former challenge poses stringent requirements on the radiometric design of the instrument to meet the targeted precision on the subpercent level for $\mathrm{XCO}_{2}$ and $\mathrm{XCH}_{4}$ and better than $10 \%$ for XCO (e.g. Bovensmann et al., 2010; Rayner et al., 2014). The slant viewing angles, in particular, challenge the employed retrieval algorithms with respect to the accurate inference of the traveled light path. Light path modification by light scattering on atmospheric particles is the dominant error source for $\mathrm{XCO}_{2}$ and $\mathrm{XCH}_{4}$ retrievals from LEO soundings (e.g. Rayner and O'Brien, 2001). Therefore, state-ofthe-art retrieval methods aim at estimating atmospheric scattering properties together with the targeted gas concentrations. But these methods are only proven under quasi-nadir viewing conditions (e.g. Oshchepkov et al., 2008; Butz et al., 2009; O'Dell et al., 2012; Polonsky et al., 2014) as typical for LEO satellites with small-to-moderate swath such as GOSAT, OCO-2, and CarbonSat. The slant viewing angles from GEO on Europe imply a long light path through the atmosphere and thus, scattering effects might have an even more prominent effect on the achievable retrieval accuracy than for quasi-nadir view.

Our study first introduces G3E's mission and instrument concept (Sect. 2) and then, shows how the radiometric design maps into prospective precision errors for the retrieved $\mathrm{XCO}_{2}, \mathrm{XCH}_{4}$, and $\mathrm{XCO}$ concentrations over the European continent (Sect. 3). Then, Sect. 4 examines retrieval performance for an illustrative ensemble of trial scenes in aerosol and cirrus loaded atmospheres. Section 5 concludes the study. Overall, our assessment focuses on the primary targets $\mathrm{XCO}_{2}, \mathrm{XCH}_{4}$, and XCO. The assessment of G3E's re- trieval capabilities for plant fluorescence and ancillary variables such as the water vapor and water isotopologue concentrations are postponed to future studies.

\section{Mission and instrument design}

The G3E instrument is an imaging grating spectrometer system with two-dimensional (2-D) array detectors that collect sunlight backscattered to the geostationary vantage point at about $35780 \mathrm{~km}$ distance from the Earth. The "horizontal" detector dimension samples the spectrum, the "vertical" detector dimension maps the ground scene in north-south (N$\mathrm{S})$ direction. The $\mathrm{N}-\mathrm{S}$ field of view of $0.9^{\circ}$ corresponds to a N-S stripe of roughly 562 and $940 \mathrm{~km}$ on the Earth's surface at the sub-satellite equatorial latitude and at $50^{\circ}$ northern latitude, respectively. The stripe is sampled by 1000 detector pixels, 3 adjacent pixels are co-added, yielding a $\mathrm{N}-\mathrm{S}$ ground sampling distance of roughly 1.7 and $3 \mathrm{~km}$ at the equator and at $50^{\circ}$ north, respectively. The east-west $(\mathrm{E}-\mathrm{W})$ direction is covered by scanning the instrument's telescope from east to west in a continuous scan pattern, where individual samples correspond to an exposure of $2.88 \mathrm{~s}$. Thus, a $2 \mathrm{~h}$ scan time allows for $2500 \mathrm{E}-\mathrm{W}$ samples. Leaving some margin for pointing operations such as a $\mathrm{N}-\mathrm{S}$ repointing step, G3E is able to cover the central European continent as illustrated in Fig. 1 within $2 \mathrm{~h}$ with an $\mathrm{E}-\mathrm{W}$ ground sampling distance of $\sim 1.7 \mathrm{~km}$ (at the sub-satellite longitude). Given small ground pixel sizes and relatively long exposures for a single sounding, G3E's satellite platform must feature precise and stable pointing capabilities. Absolute pointing accuracy, amounting to $0.2-1.5 \times 10^{-3} \mathrm{rad}$, is less critical than pointing stability which is estimated to $5 \times 10^{-6}$ rad over $2 \mathrm{~s}$. Pointing speed including settling down to start over a new E-W scan is on the order of $30 \mathrm{~s}$.

The optical setup is sketched in Fig. 2. The instrument consists of four grating spectrometers that are fed by a common telescope with $19 \mathrm{~cm}$ diameter and downstream beam splitting optics. The spectrometer channels are equipped with four separate gratings, the corresponding collimator optics $(966 \mathrm{~mm}$ focal length) and four detector units. The $f$ number (ratio of focal length to diameter) amounts to 5.1. The channels, listed in Table 1, cover the $\mathrm{O}_{2} \mathrm{~A}$-band around $760 \mathrm{~nm}$ wavelength (NIR), the weak $\mathrm{CO}_{2}$ and $\mathrm{CH}_{4}$ absorption bands around 1610 and $1650 \mathrm{~nm}$ wavelengths (SWIR$1)$, the strong water vapor $\left(\mathrm{H}_{2} \mathrm{O}\right)$ and $\mathrm{CO}_{2}$ bands between 1925 and $2080 \mathrm{~nm}$ wavelengths (SWIR-2), and the strong $\mathrm{CH}_{4}$ and $\mathrm{H}_{2} \mathrm{O}$ bands and weak $\mathrm{CO}$ bands around $2350 \mathrm{~nm}$ wavelength (SWIR-3). These channels enable the retrieval of the target quantities $\mathrm{XCO}_{2}, \mathrm{XCH}_{4}$, and $\mathrm{XCO}$ together with ancillary information on atmospheric scattering properties. In addition, the SWIR-2 channel covers strong $\mathrm{H}_{2} \mathrm{O}$ absorption lines which can be used for screening scenes contaminated by scattering particles at high altitude such as cirrus clouds (Guerlet et al., 2013b). Interfering absorption of $\mathrm{H}_{2} \mathrm{O}$ 


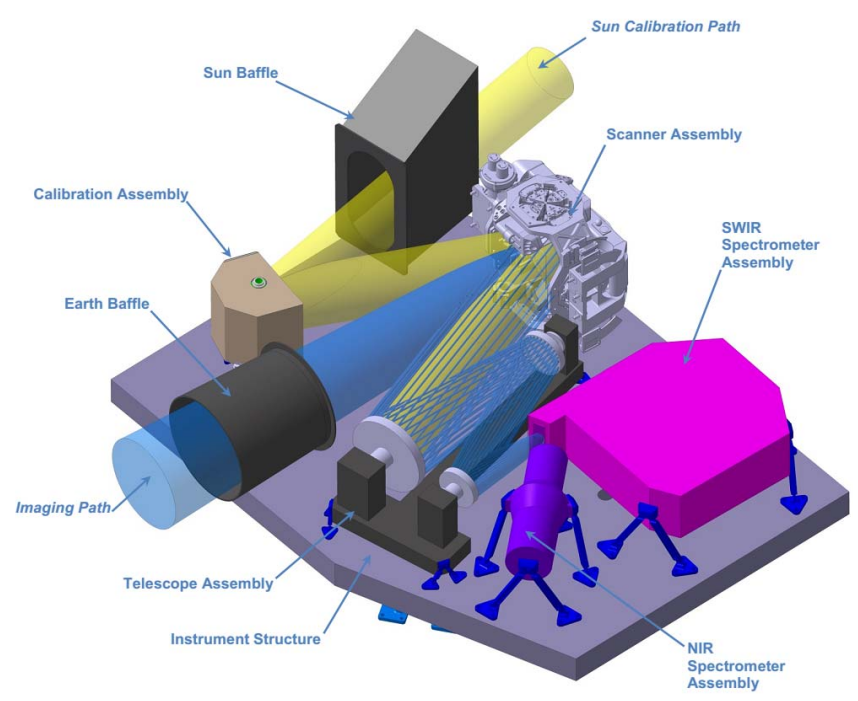

Figure 2. Sketch of the G3E instrument. Sunlight backscattered by the Earth enters the instrument through the "Earth Baffle" from the lower left into the telescope consisting of the "Scanner Assembly" and several mirrors that direct the incoming light into beam splitting optics (not visible) feeding the four spectrometers. The three SWIR spectrometers share a housing. For calibration purposes, the Scanner Assembly is able to point toward the "Calibration Assembly" which either operates calibration lamps or LEDs (light emitting diodes) or collects direct sunlight through the "Sun Baffle". The dimensions of the instrument are roughly $1600 \times 1300 \times 800 \mathrm{~mm}$ (length $\times$ width $\times$ height).

and its deuterated isotopologue (HDO) in SWIR-1, SWIR2, and SWIR-3 might allow for defining the respective concentration retrievals as secondary goals of the G3E mission. The NIR channel extends to wavelengths as short as $745 \mathrm{~nm}$ to cover several Fraunhofer lines in overlap with the broadband emission signal from plant chlorophyll fluorescence (e.g. Frankenberg et al., 2011). Figure 3 depicts simulated G3E soundings for a relatively dark reference scene with solar zenith angle $70^{\circ}$ and a Lambertian surface albedo of 0.1 in all bands. This reference scene has been used to drive the instrument design toward a signal-to-noise ratio (SNR) of roughly 150 in the continuum of all channels.

The selection of spectral channels is the classic suite of absorption bands such as used in various combinations by SCIAMACHY, GOSAT, OCO-2, CarbonSat, S5, S5P, and GEO-CARB. G3E's baseline design assumes 1000 available detector pixels for the NIR, SWIR-1, and SWIR-3 channels, and 2000 detector pixels for the SWIR-2 channel mapping into moderate spectral resolving power among the four channels (see Table 1). Detector properties are adopted from the Sofradir Next Generation Panchromatic Detector that currently provides $1024 \times 1024$ pixels. Depending on future progress in detector technology and the available cost margin, advancements of the G3E mission concept will investigate the use of 2000 pixel detectors for all channels or, in case
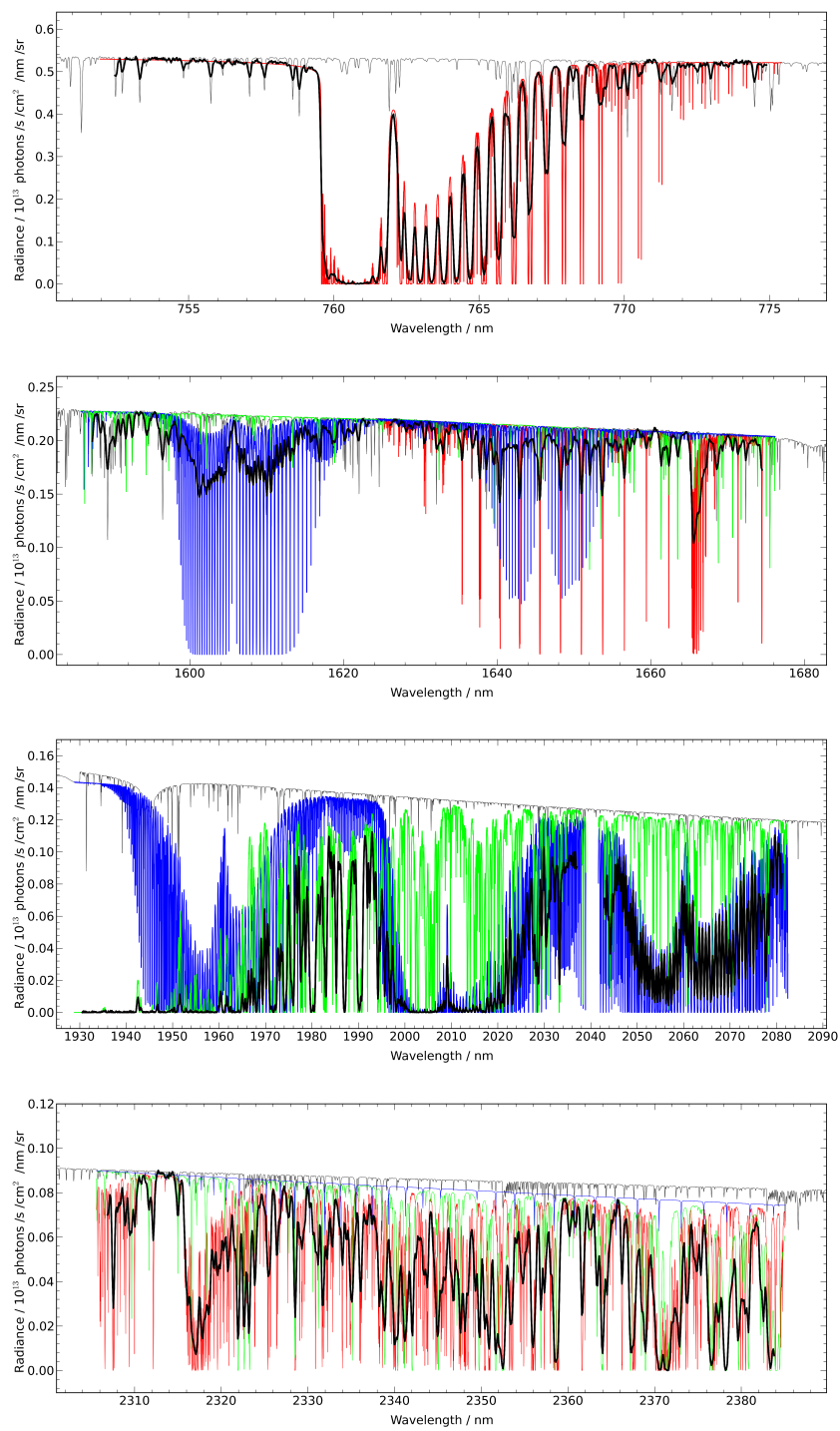

Figure 3. Backscattered radiance spectra for G3E's NIR (upper), SWIR-1 (upper middle), SWIR-2 (lower middle), and SWIR-3 (lower) channels. The thin light gray spectrum in the background is the solar Fraunhofer spectrum (scaled to fit the figure, in arbitrary units), the black bold lines in the foreground are simulated G3E measurements for the reference scene with $\mathrm{SZA}=70^{\circ}$ and albedo 0.1 , assuming a Gaussian instrument response function. The colored thin lines illustrate absorption by various molecular absorbers assuming single-molecule atmospheres at infinite spectral resolution. (upper) $\mathrm{O}_{2}$ red; (upper middle) $\mathrm{CO}_{2}$ blue, $\mathrm{CH}_{4}$ red, $\mathrm{H}_{2} \mathrm{O}$ green; (lower middle) $\mathrm{CO}_{2}$ blue, $\mathrm{H}_{2} \mathrm{O}$ green; (lower) $\mathrm{CH}_{4}$ red, $\mathrm{H}_{2} \mathrm{O}$ green, $\mathrm{CO}$ blue. Spectral windows are not exactly the ones listed in Table 1 but the ones used for retrieval simulations.

such detectors are not at hand, the accommodation of SWIR2 on a 1000 pixel detector, e.g. by cutting the strong $\mathrm{H}_{2} \mathrm{O}$ band from SWIR-2 or by degrading its spectral resolution. Implementing 2000 pixel detectors for all channels would be an appealing option since spectral coverage or spectral 
resolution could be enhanced. The NIR channel, for example, could be extended toward shorter wavelength to cover a larger portion of the emission signal from plant fluorescence. The SWIR-1 channel could cover an additional $\mathrm{CO}_{2}$ absorption band on its shortwave side to further enhance the information on $\mathrm{CO}_{2}$. The SWIR-3 channel could benefit from enhanced spectral resolution to better disentangle the overlapping absorption by $\mathrm{CH}_{4}$ and $\mathrm{H}_{2} \mathrm{O}$ provided that the required SNR can be achieved.

G3E's primary focus region, investigated here, is central Europe such as illustrated in Fig. 1. Europe is a challenging target for geostationary satellites and for satellites in general, if they rely on sunlit conditions. Viewing zenith angles (VZAs) under which a satellite in GEO above $0^{\circ}$ latitude/longitude observes Europe range between $40^{\circ}$ for southern Europe and $70^{\circ}$ for southern Scandinavia. The daily range of solar zenith angle (SZA) varies seasonally allowing for more than 10 daylight hours $\left(\mathrm{SZA}<70^{\circ}\right)$ in summer and less than 2 daylight hours in winter $\left(\mathrm{SZA}<70^{\circ}\right)$ for central Europe. Likewise, the scattering angle between the incoming downward sunbeam and the backscattered upward beam arriving at the satellite varies with season and daytime hour. For the example Berlin $\left(52.53^{\circ} \mathrm{N}, 13.38^{\circ} \mathrm{E}\right)$, the scattering angles to be encountered range between roughly $90^{\circ}$ and $180^{\circ}$ (assuming the additional constraint SZA $<70^{\circ}$ ), where the most shallow angles occur in the morning and evening during summer. The backscattering direction occurs around noon when the sun tends to be in the back of the satellite. Typically, scientific data reduction techniques are considered reliable up to VZA and SZA of $70^{\circ}$. Above that threshold, sphericity of the Earth and three-dimensional (3-D) radiative transfer effects play an increasingly prominent role. Considering such effects routinely in data reduction techniques is possible in principle, but computational cost is overwhelming for current generation computers and satellite data rates. Further, the reflectance from Lambertian surfaces scales with $\cos (\mathrm{SZA})$ such that large SZA imply low signal levels and a low signal-to-noise ratio which in turn makes retrievals more susceptible to various error sources. Therefore, G3E is not planned to address northern European latitudes and the number of central European revisits per day varies seasonally. In winter, sampling of central Europe is limited to a single revisit like for LEO satellites, in summer up to six scans can be run. To best exploit the seasonally varying illumination conditions, G3E features pointing capabilities to allow for targeting other focus regions such as Africa, western Asia, or eastern South America when Europe is too dark to deliver a useful solar backscatter signal.

Beside limitations due to slant viewing and solar angles, solar backscatter techniques in the SWIR suffer from the low diffuse reflectivity of the water surface. LEO satellites such as GOSAT and OCO-2 partially overcome this limitation by pointing at the specular reflection point in ocean-glint geometry, where water reflectivity is high. In GEO orbit, targeting the glint-spot could be an option for low-latitudes but is not useful for European target regions. Therefore, G3E's sounding capabilities are restricted to continental land surfaces. Coverage toward the Asian continent could be optimized by deploying the satellite at low eastern longitudes. The exact satellite location, however, needs to be balanced between coverage toward Asia and potential synergies when flying in close formation with the MTG satellites.

\section{Prospective noise performance}

The mission concept outlined in Sect. 2 relies on small ground-pixel sizes observed through minute solid angles from geostationary orbit. Thus, it is crucial to verify the noise characteristics of the prospective G3E soundings.

\subsection{The G3E noise model}

A detailed noise model calculates the signal-to-noise ratio (SNR). It assumes that the spectrometers integrate the radiance $L_{\lambda}$ backscattered by the Earth's surface and atmosphere over the solid angle $\Delta \Omega$ spanned by a surface-normal ground pixel with geometric dimensions $d_{\mathrm{SSP}}^{2}=1.7^{2} \mathrm{~km}^{2}$ observed from a distance $d_{\text {geo }}=35786 \mathrm{~km}$. Assuming small $\Delta \Omega$, the spectral irradiance $E_{\lambda}$ hitting G3E's telescope is given by

$E_{\lambda}=L_{\lambda} \times \Delta \Omega=L_{\lambda} \times \frac{d_{\text {SSP }}^{2}}{d_{\text {geo }}}$.

The number of photoelectrons counted by a detector pixel is given by

$N_{\mathrm{e}}=E_{\lambda} \times(d / 2)^{2} \pi \times T \times Q \times \Delta \lambda \times T_{\text {int }}$.

with $d=19 \mathrm{~cm}$ the aperture of G3E's telescope, $T=0.4$ the total transmission of the optics, $Q=0.8$ the detectors' quantum efficiencies, $\Delta \lambda$ the small wavelength interval covered by a detector pixel, and $T_{\text {int }}=2.88 \mathrm{~s}$ the available exposure time. The corresponding shot noise is $\sigma_{\mathrm{e}}=\sqrt{N_{\mathrm{e}}}$.

The noise model further accounts for contributions from background thermal emission of the spectrometer system, dark current noise and readout noise of the detectors. The latter two contributions are provided by the detector manufacturer, $\sigma_{\mathrm{e}, \text { dark }}$ and $\sigma_{\mathrm{e} \text {,readout. Thermal emission of the cryo- }}$ genic spectrometer box is given by its blackbody emission $L_{\lambda, \mathrm{BB}}\left(T_{\text {cryo }}\right)$ with $T_{\text {cryo }}=200 \mathrm{~K}$. We assume that the detector integrates over a hemispheric solid angle $\Delta \Omega_{D}=2 \pi$ and an area $A_{\text {det }}=d_{\text {det }}^{2} n_{\text {bin }}$, where $d_{\text {det }}=15 \mu \mathrm{m}$ is the detectors' pixel pitch and $n_{\text {bin }}=3$ is the number of binned pixels in spatial dimension. Further, the detector accepts radiation for wavelengths between $\lambda_{\text {lo }}=300 \mathrm{~nm}$ and $\lambda_{\text {up }}=2500 \mathrm{~nm}$ over which $L_{\lambda, \mathrm{BB}}$ needs to be integrated. Thus, the number of background thermal electrons reads

$N_{\text {e,back }}=\int_{\lambda_{\text {lo }}}^{\lambda_{\text {up }}} L_{\lambda, \text { BB }} \mathrm{d} \lambda \times \Delta \Omega_{D} \times A_{\text {det }} \times Q \times T_{\text {int }}$ 
Table 1. Spectroscopic properties of the G3E spectrometer system. Spectral resolution is given in terms of full width half maximum (FWHM) of the instrument spectral response function (ISRF) under the assumption that the given width is sampled by 3 detector pixels. Signal-to-noise (SNR) requirements are listed for the expected solar irradiance $\left(L_{\text {sun }}\right)$ and a backscattered radiance $\left(L_{\text {ref }}\right)$ corresponding to a relatively dark reference scene $\left(\right.$ albedo $\left.=0.1, \mathrm{SZA}=70^{\circ}\right)$.

\begin{tabular}{|c|c|c|c|c|c|c|c|c|}
\hline Band ID & Spectral range/nm & $\begin{array}{r}\text { Target absorbers } \\
\text { parameters }\end{array}$ & $\begin{array}{r}\text { FWHM } \\
(3 \text { pix }) / \mathrm{nm}\end{array}$ & $\begin{array}{r}\text { Pixel } \\
\#\end{array}$ & $\begin{array}{r}\text { SNR } \\
@ \text { Lref }\end{array}$ & $\begin{array}{r}\text { SNR } \\
@ \text { Lsun }\end{array}$ & $\begin{array}{r}L_{\mathrm{ref}} /(\text { photons } \\
\left.\mathrm{s}^{-1} \mathrm{~nm}^{-1} \mathrm{~cm}^{-2} \mathrm{sr}^{-1}\right)\end{array}$ & $\begin{array}{r}L_{\mathrm{sun}} /(\text { photons } \\
\left.\mathrm{s}^{-1} \mathrm{~nm}^{-1} \mathrm{~cm}^{-2}\right)\end{array}$ \\
\hline NIR & $745-775$ & $\begin{array}{r}\mathrm{O}_{2}, \\
\text { plant fluorescence, } \\
\text { light path }\end{array}$ & 0.10 & 900 & 150 & 10000 & $5.1 \times 10^{12}$ & $4.7 \times 10^{14}$ \\
\hline SWIR-1 & $1585-1675$ & $\mathrm{CO}_{2}, \mathrm{CH}_{4}, \mathrm{H}_{2} \mathrm{O}$ & 0.30 & 900 & 150 & 5000 & $2.2 \times 10^{12}$ & $2.0 \times 10^{14}$ \\
\hline SWIR-2 & 1925-2082 & $\begin{array}{r}\mathrm{CO}_{2}, \mathrm{H}_{2} \mathrm{O} \\
\text { light path }\end{array}$ & 0.25 & 1884 & 150 & 5000 & $1.3 \times 10^{12}$ & $1.2 \times 10^{14}$ \\
\hline SWIR-3 & $2305-2385$ & $\begin{array}{r}\mathrm{CH}_{4}, \mathrm{CO}, \mathrm{H}_{2} \mathrm{O}, \\
\text { light path }\end{array}$ & 0.25 & 960 & 150 & 5000 & $8.5 \times 10^{11}$ & $7.8 \times 10^{13}$ \\
\hline
\end{tabular}

yielding the corresponding background noise contribution $\sigma_{\mathrm{e}, \text { back }}=\sqrt{N_{\mathrm{e}, \text { back }}}$. The total noise $\sigma_{\mathrm{e}, \text { tot }}$ adds up to

$\sigma_{\mathrm{e}, \mathrm{tot}}=\sqrt{\sigma_{\mathrm{e}}^{2}+\sigma_{\mathrm{e}, \mathrm{back}}^{2}+\sigma_{\mathrm{e}, \mathrm{dark}}^{2}+\sigma_{\mathrm{e}, \text { readout }}^{2}}$

and SNR is given by $N_{\mathrm{e}} / \sigma_{\mathrm{e} \text {,tot }}$. Figure 4 depicts the corresponding SNR of the continuum radiance at various wavelengths in the vicinity of the relevant gas absorption bands. The instrument is designed to meet $\mathrm{SNR}=150$ for the reference scene with Lambertian surface albedo 0.1 and $\mathrm{SZA}=70^{\circ}$.

\subsection{The "non-scattering" trial ensemble}

The brightness of the scenes and thus, the SNR to be encountered by G3E is largely driven by surface albedo and SZA. To test G3E's performance with respect to noise propagation into the target parameters $\mathrm{XCO}_{2}, \mathrm{XCH}_{4}$, and $\mathrm{XCO}$, we collect an ensemble of surface albedo observed by the MODIS (Moderate Resolution Imaging Spectroradiometer) satellite in several spectral bands throughout the NIR and SWIR spectral range. We use the MODIS MCD43A4 product which provides albedo soundings aggregated over 16 days with $500 \mathrm{~m}$ horizontal resolution. We sample the MODIS product enclosing the 16th day of January, April, July, and October at the center of each $0.1^{\circ} \times 0.1^{\circ}$ (latitude $\times$ longitude) box in a grid covering central and southern Europe and adopt MODIS albedo as Lambertian albedo term in our measurement simulations. We further collect an ensemble of gas concentrations. $\mathrm{CO}_{2}$ concentrations are read from CarbonTracker (Peters et al., 2007) model output for the year 2010. $\mathrm{CH}_{4}$ and $\mathrm{CO}$ are read from a TM4 (Tracer model 4) run for the year 2006 (Meirink et al., 2006). Pressure, temperature and $\mathrm{H}_{2} \mathrm{O}$ abundances stem from a run of the ECHAM5HAM model (Stier et al., 2005). The gas concentrations are provided at much coarser horizontal resolution (coarser than $2^{\circ} \times 3^{\circ}$ ) than the albedo ensemble. We interpolate the gas fields to the $0.1^{\circ} \times 0.1^{\circ}$ grid albeit model variability is not representative of such fine resolution. However this is not

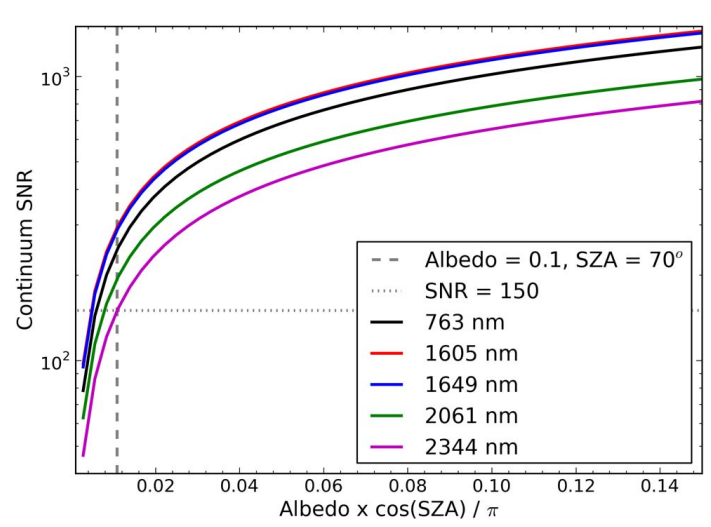

Figure 4. Signal-to-noise ratio (SNR) in the continuum of the backscattered radiance vs. scene brightness for various wavelengths (see legend). Scene brightness is given by albedo $\times \cos (\mathrm{SZA}) / \pi$, i.e. the reflectance of a transparent atmosphere above a Lambertian surface.

relevant for our noise assessment study. Overall, the ensemble setup is very similar to previous simulation studies conducted in support of SCIAMACHY, GOSAT, OCO-2, and S5P (e.g. Butz et al., 2012) but with a much finer sampling of the underlying albedo ensemble. Figure 5 shows the collected albedo ensemble for G3E's SWIR-1 channel as an example.

The European trial ensemble feeds our radiative transfer and retrieval algorithm "RemoTeC" to simulate an ensemble of G3E-like soundings, much alike Fig. 3, assuming that observations are conducted from GEO above $0^{\circ}$ latitude/longitude at 12:00 UTC on the 16th day in January, April, July, and October. The sounding simulations take MODIS albedo at $860 \mathrm{~nm}$ as representative for G3E's NIR channel, MODIS albedo at $1640 \mathrm{~nm}$ for G3E's SWIR-1 channel, MODIS albedo at $2130 \mathrm{~nm}$ for G3E's SWIR-2 channel. Albedo in G3E's SWIR-3 channel is extrapolated from MODIS albedo at $2130 \mathrm{~nm}$ through scaling by a factor 0.7 which is a rough estimate derived from reflection properties 


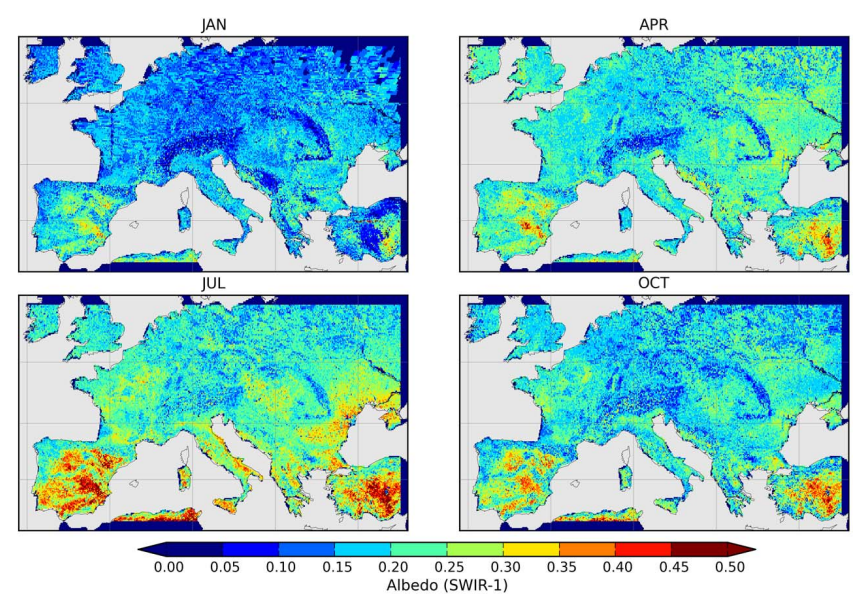

Figure 5. Lambertian surface albedo adopted for the European trial ensemble in the SWIR-1 channel (at $1640 \mathrm{~nm}$ ) for the months January (JAN), April (APR), July (JUL), and October (OCT).

of vegetation surfaces. The spectroscopic parameters translating the gas abundances into atmospheric absorption spectra are taken from spectroscopic databases as used for our RemoTeC GOSAT retrievals (e.g. Butz et al., 2011). For the noise assessment here, RemoTeC assumes a purely absorbing, "non-scattering" atmosphere above a Lambertian surface which enables computationally efficient processing of the trial ensemble. A Gaussian instrument line shape convolves the simulated atmospheric spectra to instrument resolution (according to Table 1) and our noise model, described above, calculates the SNR for each sounding and each detector pixel.

\subsection{The non-scattering retrieval simulations}

Given the ensemble of trial spectra, the non-scattering variant of RemoTeC selects the retrieval windows indicated in Fig. 3 (bold black lines) and retrieves the target parameters $\mathrm{XCO}_{2}$, $\mathrm{XCH}_{4}$, and XCO. The simulated SNR is propagated into a statistical error estimate according to the rules of Gaussian error propagation (e.g. Rodgers, 2000). RemoTeC is based on a Philipps-Tikhonov regularization scheme (Phillips, 1962; Tikhonov, 1963) that uses the first-order difference operator as a side-constraint to retrieve the $\mathrm{CO}_{2}, \mathrm{CH}_{4}$ and $\mathrm{CO}$ partial column profiles (units molec $\mathrm{cm}^{-2}$ ). Here, we allow for roughly 1 degree-of-freedom for the vertical profiles. Ancillary retrieval parameters are the total column $\mathrm{H}_{2} \mathrm{O}$ concentrations and a second-order albedo polynomial per retrieval window. The column-average mixing ratios (units $\mathrm{ppm}$ ) of $\mathrm{XCO}_{2}, \mathrm{XCH}_{4}$, and $\mathrm{XCO}$ are calculated by summing over all vertical layers and dividing by the known (and true) vertical air column. The setup chosen for the noise assessment here is consistent between the retrieval and simulation approach; i.e. the retrievals and simulations incorporate the exact same physical processes and implementations, and thus, retrievals can find the true parameter values except for statistical noise errors. A consistent setup is chosen to isolate the statistical noise error from other error sources. Section 4 introduces an additional forward model error by making the simulation and retrieval forward model inconsistent.

\subsection{Noise errors}

Figures 6 through 8 depict the retrieval noise errors for $\mathrm{XCO}_{2}, \mathrm{XCH}_{4}$, and $\mathrm{XCO}$. For illustration purposes, scenes with $\mathrm{SZA}<70^{\circ}$ are not screened although retrievals in a real-world setting might be difficult. $\mathrm{XCO}_{2}$ and $\mathrm{XCH}_{4}$ exhibit noise errors mostly lower than $0.5 \%$, except for regions and seasons, where the sun is low and the infrared surface albedo is dark such as in winter time Europe for snowcovered surfaces. XCO noise errors are typically below $10 \%$ and show a similar seasonal and geographic pattern as found for the $\mathrm{XCO}_{2}$ and $\mathrm{XCH}_{4}$ estimates. Overall, G3E's instrument design with small ground-pixel size and a relatively large telescope delivers a noise performance that complies with the requirements on retrieval precision for a state-ofthe-art greenhouse gas sounder. Some scenes in winter-time Europe require screening since large SZA and low infrared surface albedo limit the number of backscattered photons there.

\section{Retrieval simulations under particle loaded conditions}

Errors due to inaccurate knowledge of the light path have been identified as a major challenge of solar backscatter $\mathrm{XCO}_{2}$ and $\mathrm{XCH}_{4}$ soundings (e.g. Rayner and O'Brien, 2001). Generally, aerosols and other airborne particles scatter the incoming solar radiation which results in light path modification compared to a non-scattering atmosphere. Light paths can be shorter or longer than in the non-scattering case depending on the particle abundances, particle height distributions, and particle microphysical properties as well as on the reflection properties of the Earth's surface (e.g. Butz et al., 2013). If scattering-induced light path modification is not known accurately, the observed gas absorption along the light path is attributed to wrong gas concentrations. Therefore, current state-of-the art retrieval algorithms such as our RemoTeC have the capability to simultaneously retrieve atmospheric scattering and gas absorption properties.

Here, we provide an initial assessment of how well a G3Elike concept is able to account for scattering-related light path modification in retrievals of its targeted gas concentrations. For the sake of conciseness, we focus discussion on retrieval performance for $\mathrm{XCO}_{2}$ since implications mostly hold in analogy for $\mathrm{XCH}_{4}$ and requirements are more challenging for $\mathrm{XCO}_{2}$ than for $\mathrm{XCH}_{4}$. Scattering-induced retrieval errors for $\mathrm{XCO}$ are less critical than for the greenhouse gases since 

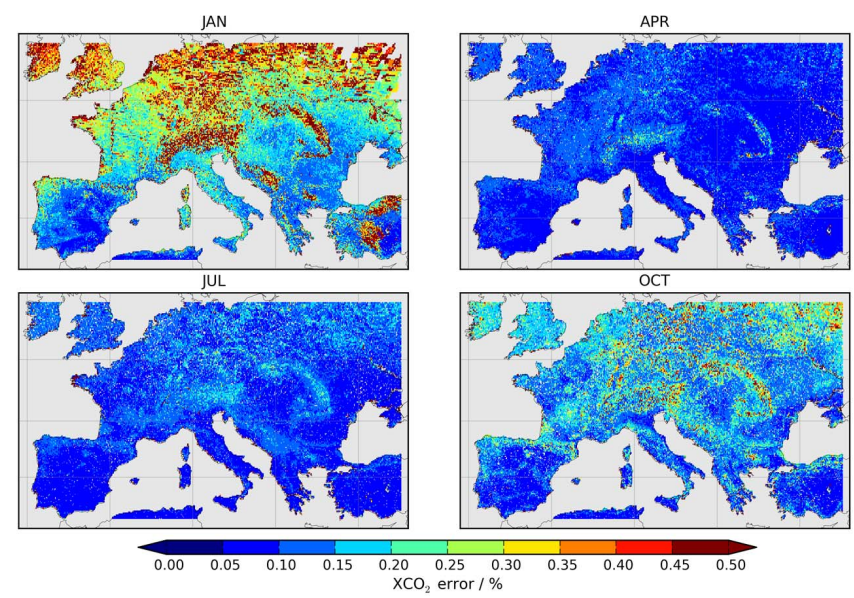

Figure 6. Relative $\mathrm{XCO}_{2}$ noise error among the European trial ensemble expected from G3E for the months January (JAN), April (APR), July (JUL), and October (OCT).
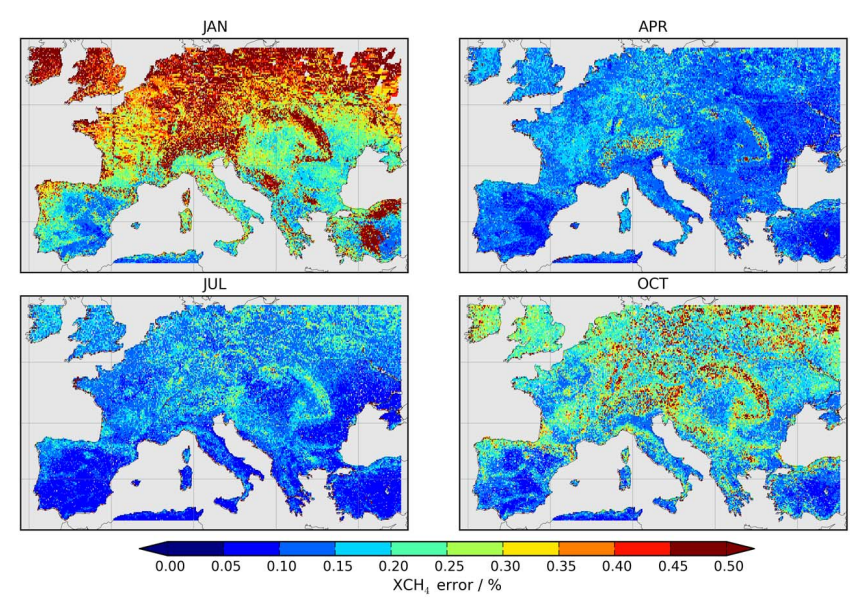

Figure 7. Relative $\mathrm{XCH}_{4}$ noise error among the European trial ensemble expected from G3E for the months January (JAN), April (APR), July (JUL), and October (OCT).

accuracy requirements are less stringent and noise errors play a more prominent role (Fig. 8, Vidot et al., 2012).

\subsection{The "scattering" trial ensemble}

Previously, we have assessed the performance of various LEO satellites with respect to reducing residual scatteringinduced retrieval errors (Butz et al., 2009, 2010, 2012). We used a global trial ensemble of atmospheric aerosol and cirrus properties and performed extensive retrieval simulations. Here, we use a similar trial ensemble to investigate G3E's ability to cope with aerosol and cirrus scattering and to identify potential challenges to be addressed by future improvements of radiative transfer and retrieval algorithms or by improved instrument design.
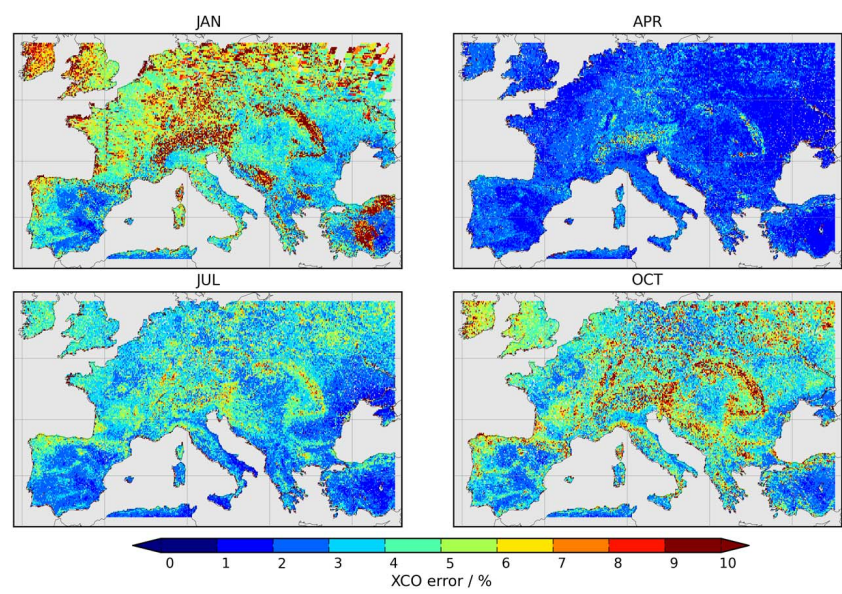

Figure 8. Relative XCO noise error among the European trial ensemble expected from G3E for the months January (JAN), April (APR), July (JUL), and October (OCT).

For this initial performance assessment, we simply pretend that the global trial ensemble, much like the one previously used for LEO satellites, is observed under solar and viewing angles that correspond to G3E's view on Europe at 12:00 UTC. Originally, the ensemble extended from -90 to $+90^{\circ}$ latitude and from -180 to $+180^{\circ}$ longitude. Here, we define a linear rule that maps the original extent to the region 35 to $55^{\circ}$ latitude and -15 to $45^{\circ}$ longitude. Then, we calculate the solar and viewing angles for the mapped coordinates, simulate G3E soundings and perform simulated retrievals. The approach has the advantage that the scattering parameters driving the simulation are comparable to the ones in previous assessments; thus, G3E's performance can be put in relation to previous studies. The tacit assumption is that the global ensemble of particle scattering and surface reflection properties is representative of the range of conditions to be encountered by G3E when observing Europe.

The geophysical trial ensemble builds on the collection of Lambertian surface albedo and gas concentrations defined in Sect. 3 , but the sampling is worldwide on a $2^{\circ} \times 2^{\circ}$ grid instead of Europe-wide on $0.1^{\circ} \times 0.1^{\circ}$. As in the non-scattering trial ensemble, we sample all input data for 4 days in January, April, July, and October resulting in more than 18000 trial scenes. Aerosol properties are fed into the ensemble by spatiotemporally interpolating output of the ECHAM5-HAM model (Stier et al., 2005) which provides the microphysical properties of seven log-normal size distributions and five chemical particle types on 19 vertical layers at $\sim 3^{\circ} \times 3^{\circ}$ horizontal resolution. Aerosol optical properties are calculated from the chemical and physical properties through a Mie model assuming spherical shape of the particles. The modeled aerosol optical thickness (at $550 \mathrm{~nm}$ ) is scaled to the monthly median observed by MODIS on a $1^{\circ} \times 1^{\circ}$ grid in the year 2007 for locations where MODIS MOD08 products are available. Where no MODIS data are available, we scale 


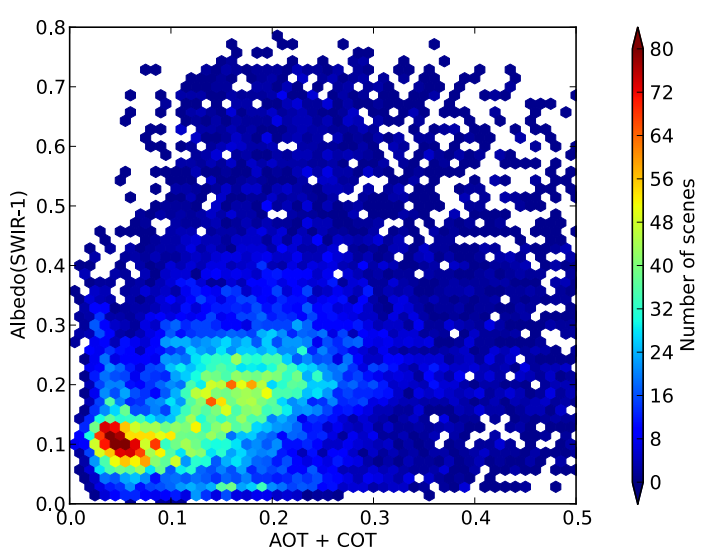

Figure 9. Ensemble of surface albedo at SWIR-1 and scattering optical thickness (aerosol plus cirrus optical thickness, AOT + COT) at $550 \mathrm{~nm}$ used for the full-physics retrieval simulations. The color scale counts occurrence of scenes.

aerosol optical thickness to the overall range of MODIS observations. Cirrus optical thickness and height distributions are the median values read from a monthly climatology of CALIOP (Cloud-Aerosol Lidar with Orthogonal Polarization) thin cirrus observations in the year 2007 (Winker et al., 2007). Cirrus optical properties rely on the ray-tracing model of Hess and Wiegner (1994) and Hess (1998) assuming hexagonal particles with sizes between 0.003 and $1.3 \mathrm{~mm}$. The effective scattering phase function used for the radiative transfer calculations is a composite constructed from contributions by the various types of spherical Mie aerosols and hexagonal ice crystals. The contributions from the seven size modes of Mie aerosol and the cirrus particles are weighted by their respective optical thickness. Overall, the aerosol and cirrus ensemble is similar to the one extensively described in Butz et al. $(2009,2010,2012)$ though sampling here is at slightly finer resolution. Figure 9 illustrates occurrence of surface albedo and scattering optical thickness among our trial ensemble. It clearly covers the range of surface albedo and scattering optical thickness to be expected for G3E soundings above the European continent. Throughout the study, we assume that cloudy cases are screened during preprocessing.

In contrast to the previous noise assessment in Sect. 3, a "scattering" variant of $\mathrm{RemoTeC}$ calculates the ensemble of simulated soundings. It feeds the extensive collection of atmospheric scattering and absorption properties described above into a radiative transfer model that calculates the absorption spectra in a scattering and absorbing atmosphere. Measurement noise for GEO is calculated via the noise model described in Sect. 3. For the LEO simulations conducted for comparison, we assume the same noise as in GEO.

\subsection{The full-physics retrieval simulations}

Given the scattering trial ensemble, $\mathrm{RemoTeC}$ then retrieves $\mathrm{XCO}_{2}$ and $\mathrm{XCH}_{4}$ (and $\mathrm{XCO}$, but not discussed here) in a retrieval configuration which is approximate compared to the simulation configuration. To this end, the state vector of retrieval parameters discussed in Sect. 3 is supplemented by four parameters describing atmospheric scattering properties: the total particle column of a boundary layer Mie-type aerosol, the total particle column of a Mie-type aerosol in an elevated layer, the center height of the elevated layer, and a parameter characterizing the size distribution of the elevated aerosol. For both, boundary-layer and elevated aerosol, the particle size distributions are power-law distributions $\left(r / r_{0}\right)^{-\alpha}$ with particle radius $r$, a normalization constant $r_{0}=10 \mu \mathrm{m}$, and the size parameter $\alpha$. The latter is retrieved for the elevated particle layer and assumed constant $\alpha=3.5$ for the boundary layer. The particle height distributions are of Gaussian shape. The boundary layer distribution has a center height of $0 \mathrm{~m}$ and a width of $2000 \mathrm{~m}$. The elevated layer has a width of $3000 \mathrm{~m}$ and its center height is retrieved. Particle refractive indices are assumed constant at 1.4 and -0.01 for the real and imaginary part, respectively. The retrieval configuration is very similar to the "full-physics" configuration used for our routine GOSAT retrievals and our simulations studies for OCO-2, GOSAT, and S5P. A slight refinement relates to the use of a two-layer aerosol distribution with four retrievable aerosol parameters instead of a single-layer distribution with three retrieval parameters used previously.

We emphasize that our approach for evaluating aerosoland cirrus-induced errors is based on simulation and retrieval forward models which are inconsistent; i.e. the retrievals and simulations differ in the implemented physics approximations. These forward model differences induce forward model errors that propagate into the retrieved gas concentrations. For example, the simulations are based on aerosol concentrations in 19 height layers without any imposed functional form of the height distribution, whereas the retrieval configuration imposes two Gaussian height layers of prescribed width and one of them fixed to the bottom of the atmosphere. Likewise, the simulations cover non-spherical cirrus and spherical Mie particles characterized by seven lognormal size distributions and various chemical types, while the retrievals impose a single Mie-particle type with prescribed refractive indices and with mono-modal size distributions. Previous simulation studies have shown that such an approach yields a good estimate of how well satellite sounders are able to reduce aerosol- and cirrus-induced errors propagating into the retrieved greenhouse gas concentrations.

\subsection{Residual aerosol- and cirrus-induced errors}

We process the trial ensemble four times: once for solar and viewing angles mimicking a geostationary view on Europe, 

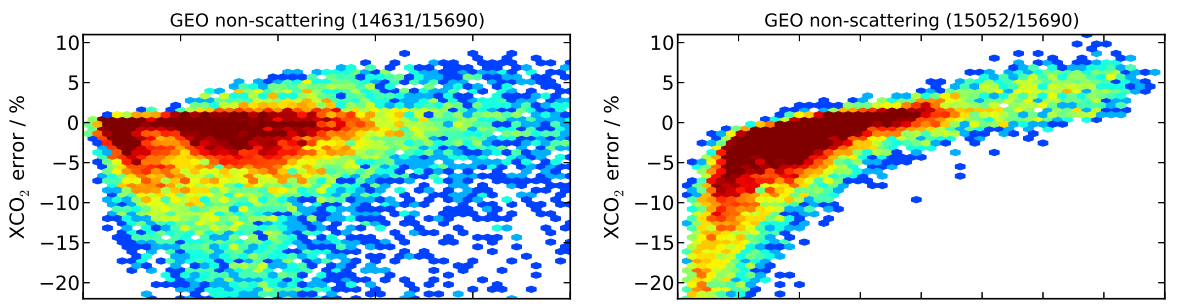

LEO full-physics (9845/10508)
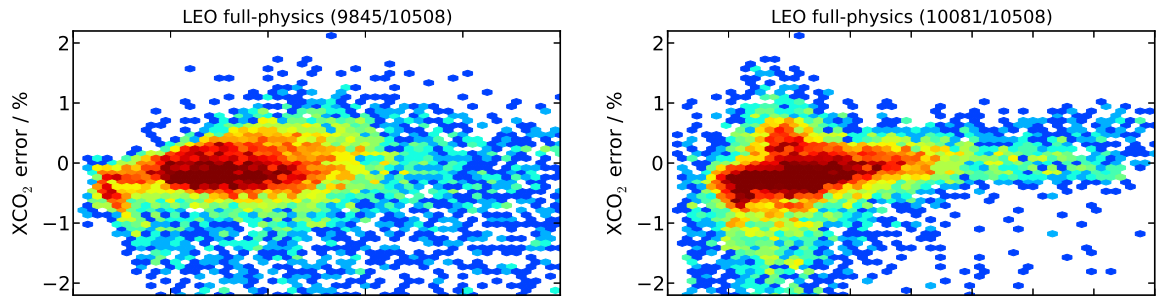

GEO full-physics (9079/10386)
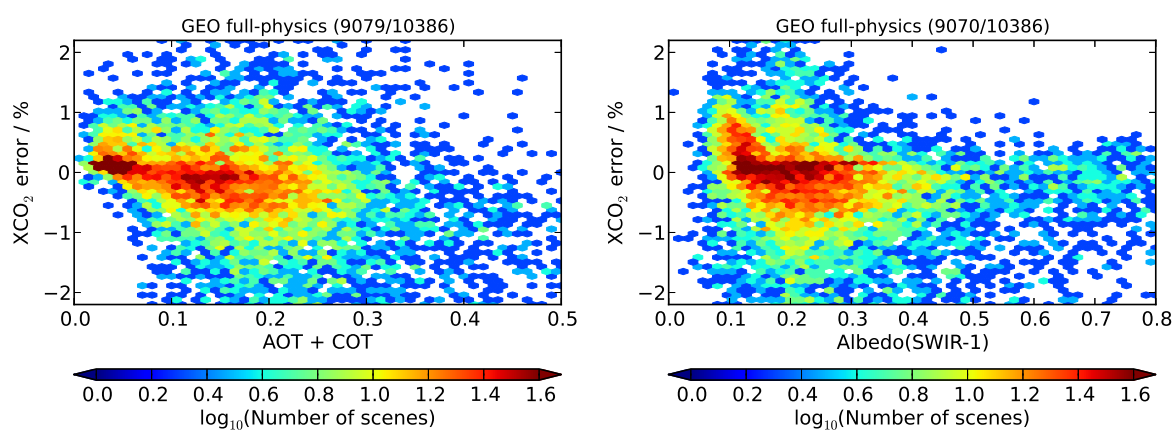

Figure 10. Relative aerosol- and cirrus-induced $\mathrm{XCO}_{2}$ forward model errors (retrieved/true - 1) for the non-scattering retrievals in GEO geometry (upper panels), for the full-physics retrievals in LEO geometry (middle panels), and for the full-physics retrievals in GEO geometry (lower panels). The left side shows errors as a function of the true aerosol and cirrus optical thickness (AOT + COT at $550 \mathrm{~nm}$ ). The right side shows the errors as a function of albedo in the SWIR-1 band. For the non-scattering retrievals, quality filters screen non-convergent behavior, ocean surfaces, VZA $>70^{\circ}$, and SZA $>70^{\circ}$. For the full-physics retrievals, SNR-limited dark scenes in SWIR-3 (albedo $\times \cos (\mathrm{SZA}) / \pi<$ $0.005)$ are screened in addition. The panel title quotes the respective retrieval configuration and the number of plotted and total scenes in parentheses (plotted/total). The difference (total - plotted) is the number of outlier retrievals beyond the axes scales. The color scale shows logarithmic occurrence. Note that the middle and lower panels have identical occurrence binning, while for the upper panels the ordinate scale and occurrence binning are inflated.

once for the original view of a nadir-viewing LEO satellite overpassing each scene at 12:00 UTC, and both of these cases for the full-physics retrieval configuration and for a nonscattering configuration such as used in Sect. 3. The latter yields performance for a worst-case scenario where no effort is made to mitigate light path modification due to scattering by particles. The non-scattering retrievals only use the SWIR-1 band which is typically least affected by light path modification. The full-physics retrievals use all the spectral bands illustrated in Fig. 3. The approximate treatment of particle scattering induces forward model errors in the retrieved $\mathrm{XCO}_{2}$ and $\mathrm{XCH}_{4}$. These forward model errors are calculated by subtracting the true column-average mixing ratios from the retrieved ones. A calculation described in Butz et al. (2012), in particular Eq. (17) there, cancels the small contribution of noise errors in linear approximation of retrieval theory (e.g. Rodgers, 2000). As emphasized above, we focus discussion on $\mathrm{XCO}_{2}$ for the sake of conciseness.
Figure 10 illustrates the $\mathrm{XCO}_{2}$ forward model errors caused by aerosol and cirrus particles for the non-scattering GEO configuration, the full-physics LEO configuration, and the full-physics GEO configuration. All retrievals undergo basic quality filtering which removes non-convergent cases, scenes with large viewing and solar zenith angles (VZA > $70^{\circ}, \mathrm{SZA}>70^{\circ}$ ), and ocean surfaces with very low albedo. For the full-physics configurations, we additionally screen retrievals with low SNR (Albedo(SWIR-3) $\times \cos (\mathrm{SZA}) / \pi<$ 0.005 ). After quality filtering, the total number of retrievals is more than 15000 for the non-scattering configuration and more than 10000 for the full-physics configurations.

The non-scattering retrievals, Fig. 10 (upper panels), confirm previous findings that the neglect of particle scattering effects yields exceedingly large $\mathrm{XCO}_{2}$ residual errors. The residual errors correlate with the surface albedo of the scene. Dark surfaces cause underestimation of the true $\mathrm{XCO}_{2}$ concentration i.e. the true light path is shorter than the one in the assumed non-scattering atmosphere. For bright scenes, 

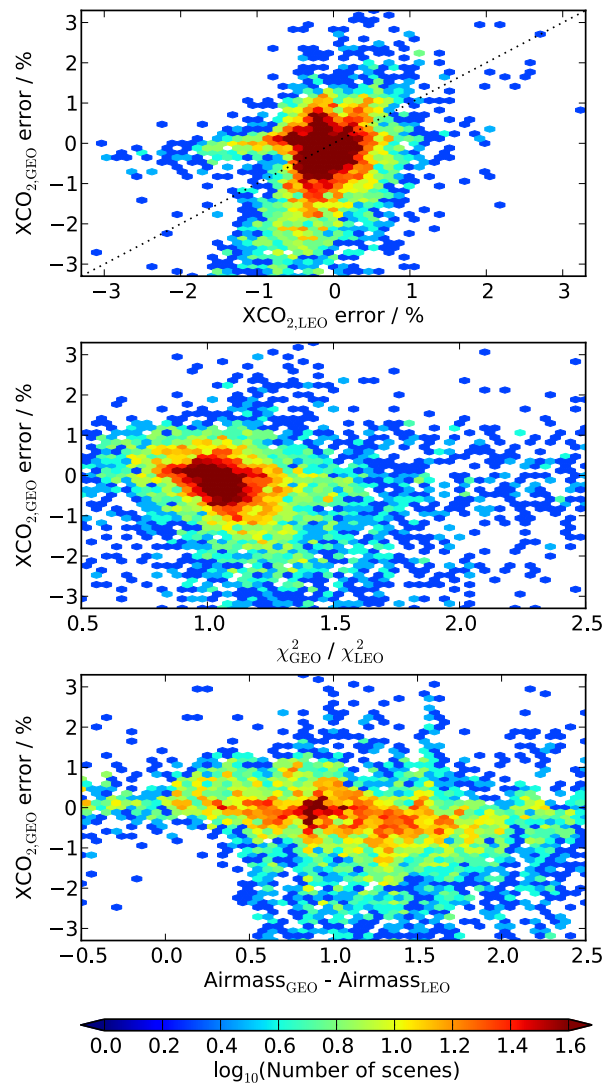

Figure 11. Relative aerosol- and cirrus-induced $\mathrm{XCO}_{2}$ forward model errors (retrieved/true -1 ) found by the GEO configuration as a function of the relative $\mathrm{XCO}_{2}$ errors (retrieved/true - 1) in LEO configuration (upper panel), the ratio of $\chi^{2}$ in GEO and LEO configuration (middle panel), and the difference between slant air mass in GEO and LEO configuration (lower panel). $\chi^{2}$ is calculated via $\frac{1}{N_{\text {DFS }}} \sum_{i} \frac{\left(y_{i, \text { meas }}-y_{i, \text { mod }}\right)^{2}}{\sigma_{i}^{2}}$, where the sum is of all detector pixels, $i, y_{i, \text { meas }}$ and $y_{i, \bmod }$ are the measured and the modeled radiance, $\sigma_{i}$ is the noise error, and $N_{\text {DFS }}$ is the number of degrees of freedom for signal. Slant air mass is calculated via $1 / \cos (\mathrm{SZA})+1 / \cos (\mathrm{VZA})$ with solar zenith angle SZA and viewing zenith angle VZA. The color scale shows logarithmic occurrence. Note that the scale of residual $\mathrm{XCO}_{2}$ errors is inflated by a factor 1.5 compared to Fig. 10 to cover the more challenging cases.

aerosols and cirrus tend to enhance the light path over what is expected in a clear atmosphere; therefore, the non-scattering retrievals overestimate the true $\mathrm{XCO}_{2}$. For moderately bright scenes, the light path shortening and enhancing effects can cancel and fortuitously result in accurate retrievals (Butz et al., 2009).

The full-physics LEO configuration, Fig. 10 (middle panels), is able to substantially reduce aerosol- and cirrusinduced retrieval errors in comparison to the non-scattering configuration. The error patterns observed for a G3E-like satellite in LEO orbit are similar to the ones found previously for other LEO satellites (e.g. Butz et al., 2009, 2012). Most scenes allow for retrievals that are accurate to within fractions of a percent. Tentatively, the spread of residual errors increases with increasing scattering optical thickness and decreasing surface albedo. Besides its use for simulation studies, $\mathrm{RemoTeC}$ has been evaluated extensively for real $\mathrm{XCO}_{2}$ and $\mathrm{XCH}_{4}$ retrievals from the LEO satellite GOSAT (Butz et al., 2011; Schepers et al., 2012; Guerlet et al., 2013b). Performance for real LEO observations actually is better than for our trial ensemble. Our simulations tend to be challenging since assumed aerosol and cirrus abundances are based on climatological median abundances without any preferential selection of particle-free cases. Although the overall performance estimate might be pessimistic, the ensemble simulations allow for comparing performance of observational configurations as intended here.

Performance for the full-physics GEO configuration, Fig. 10 (lower panels), is worse than for LEO geometry but the majority of cases still yield residual errors of fractions of a percent. Generally, the spread of residual errors is greater in GEO than in LEO but follows similar overall patterns. Retrievals become more challenging for greater scattering optical thickness and darker surfaces. Figure 11 directly correlates the full-physics GEO and LEO retrievals for the subset of roughly 8500 cases that pass both the GEO and the LEO quality filters. Generally, most scenes produce residual $\mathrm{XCO}_{2}$ errors clustering in the sub-percent range for both geometries (Fig. 11, upper panel). The GEO configuration yields a somewhat greater fraction of low-biased retrievals. However, there is no clear evidence how these low-biased retrievals relate to retrieval parameters or geophysical conditions. Tentatively, the fitting in GEO configuration results in more cases with greater $\chi^{2}$ than in LEO (Fig. 11, middle panel), and the spread of residual errors becomes greater for worse $\chi^{2}$. Similar conclusions hold for the dependency of the GEO retrieval errors on slant air mass i.e. the length of the slant light path through the Earth's atmosphere (Fig. 11, lower panel). While the spread of $\mathrm{XCO}_{2}$ errors increases with increasing air mass for GEO compared to LEO, there is no significant overall deterioration of GEO retrieval performance for large air mass.

Figure 12 summarizes performance for the LEO, GEO, full-physics and non-scattering configurations through an occurrence count of residual forward model errors. To allow for a fair comparison, only non-scattering retrievals contribute to the counting if the scene produces also a valid full-physics retrieval in the respective configuration. LEO and GEO configurations show a similar number of retrievals with very low residual $\mathrm{XCO}_{2}$ and $\mathrm{XCH}_{4}$ errors. Performance of the GEO configuration, however, is inferior to LEO in the range of moderate residual errors up to $1 \%$. Overall, $\mathrm{XCH}_{4}$ retrievals in GEO perform generally slightly better in terms of relative errors than $\mathrm{XCO}_{2}$ retrievals. Performance for the nonscattering configuration is overall inferior.

These findings confirm that the geostationary viewing geometry on Europe is somewhat more challenging for the 

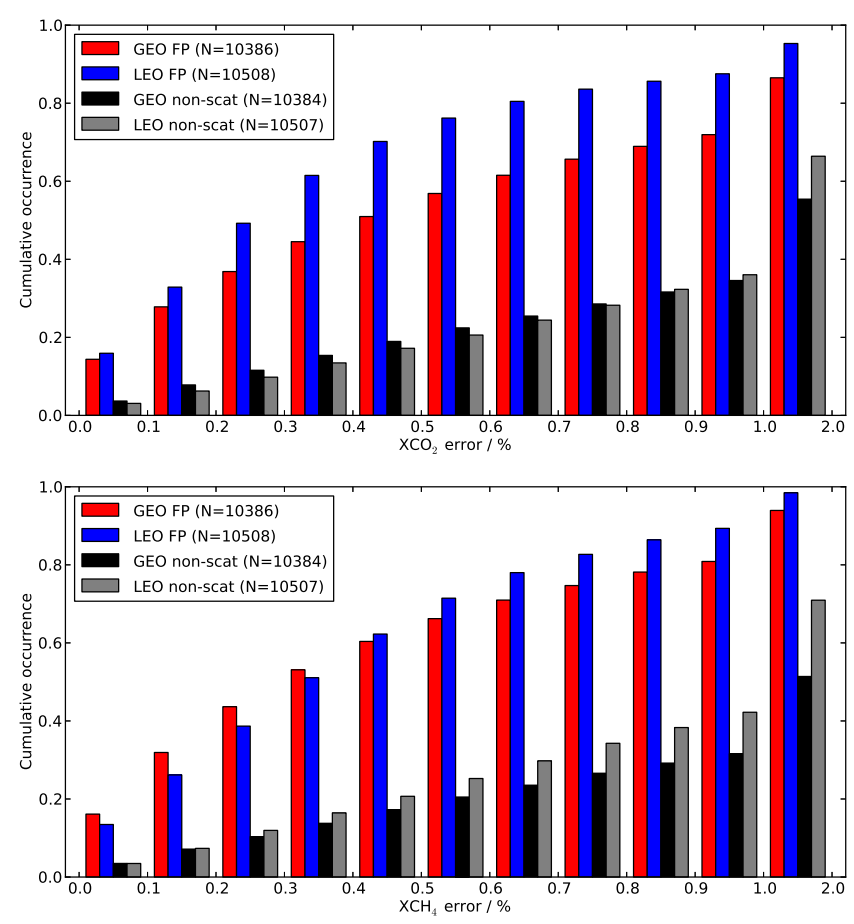

Figure 12. Cumulative relative occurrence of $\mathrm{XCO}_{2}$ (upper) and $\mathrm{XCH}_{4}$ (lower) errors for the full-physics (FP) and non-scattering (non-scat) retrievals mimicking a LEO or a GEO satellite as indicated by the legend. Number $N$ of successful retrievals as indicated by the legend. Only non-scattering retrievals that pass the corresponding full-physics retrievals are counted. Full-physics quality filters screen non-convergent behavior, ocean surfaces, $\mathrm{VZA}>70^{\circ}, \mathrm{SZA}>70^{\circ}$, and SNR-limited dark scenes in SWIR-3 (albedo $\times \cos (\mathrm{SZA}) / \pi<0.005)$.

retrieval of greenhouse gas column concentrations than the nadir-viewing geometry in LEO. Even without considering 3-D radiative transfer effects, the importance of scattering and absorption by gases and particles is enhanced, which on the one side yields enhanced information content but on the other side also comes with enhanced complications when aiming at accurately accounting for the respective effects. To mitigate these complications, Fig. 12 suggests to develop quality filters that restrict valid retrievals to the category with residual errors below $0.3 \%$ for $\mathrm{XCO}_{2}$ and $0.5 \%$ for $\mathrm{XCH}_{4}$. Such screening procedures are in regular use for retrievals from GOSAT. The most efficient ones are based on a combination of the retrieved particle parameters characterizing the difficulty of the scattering scene (Butz et al., 2011) and on the detection of thin, elevated cirrus layers in the highly absorbing $\mathrm{H}_{2} \mathrm{O}$ absorption band around $1.95 \mu \mathrm{m}$ wavelength (Fig. 3) (Guerlet et al., 2013b).

Given that the actual implementation of a geostationary greenhouse sounder is only to be expected in the mid-tolong-term future, progress in retrieval algorithm development might be able to further reduce the residual aerosoland cirrus-induced errors. The $\mathrm{RemoTeC}$ algorithm used here is based on an approximate parameterization of atmospheric scattering properties in particular imposing a two-layer particle height distribution. Other algorithms (e.g. O'Dell et al., 2012) implement a more sophisticated parameterization of particle types and height distributions that might be better suited to exploit the information content available from GEO.

Finally, the synergistic use of aerosol and cirrus properties available from other satellites in a similar orbit is an option that has received little attention for LEO satellites, so far. In G3E's orbit, MTG delivers a suite of atmospheric scattering properties that could be matched spatiotemporally to G3E soundings either directly or through the mediation of data assimilation tools. Then, MTG's aerosol and cloud products could be used to select clear cases suitable for G3E's processing or to set the scattering scenario to be fed into G3E's radiative transfer model.

\section{Conclusions}

G3E is a satellite mission concept for a spectrometer system to be deployed in geostationary orbit. The G3E instrument is designed to comply with the requirements previously found to enable monitoring of point-source emissions as well as diffuse biogenic sources and sinks of the greenhouse gases $\mathrm{CO}_{2}$ and $\mathrm{CH}_{4}$ (e.g. Bovensmann et al., 2010). Small ground-pixel sizes need to be combined with imaging capabilities of the ground scene to exploit the spatiotemporal context of the inferred concentration fields for contrasting foreground emission plumes from background concentrations or for disentangling meteorological advection from source/sink patterns. Ground pixels of $\sim 2 \mathrm{~km} \times 3 \mathrm{~km}$ extent (at $50^{\circ}$ latitude) and single-shot exposures of $\sim 2.9 \mathrm{~s}$ allow G3E to sample the central European continent within $2 \mathrm{~h}$ and thus to provide up to six continental-scale images per day in summer and at least one in winter when daylight hours are few.

Our SNR analysis for an ensemble of European scenes collecting seasonal surface reflection properties throughout Europe confirms that the precision to be expected for retrievals of $\mathrm{XCO}_{2}$ (mostly better than $0.5 \%$ ), $\mathrm{XCH}_{4}$ (mostly better than $0.5 \%$ ), and XCO (mostly better than $10 \%$ ) is sufficient to feed source/sink modeling. The instrument properties driving radiometric performance are an Earth-viewing telescope with a relatively large aperture $d=19 \mathrm{~cm}$, spectrometers operating at only moderate resolving powers of several 1000 , and state-of-the-art detectors. Retrieval simulations for a trial ensemble of aerosol and cirrus scattering scenes suggest that state-of-the-art retrieval algorithms can deliver $\mathrm{XCO}_{2}$ and $\mathrm{XCH}_{4}$ with accuracy in sub-percent range for the majority of cases. However, residual particle-scattering-induced errors are somewhat larger for a GEO satellite with a slant view on Europe than for a nadir-viewing LEO geometry. Since G3E is planned to operate in GEO above European longitudes in the vicinity of the MTG satellites, synergistic use of MTG's 
aerosol and cloud soundings is an appealing option to overcome that challenge.

Our study does not assess the potential impact of error sources other than random radiometric noise- and scatteringinduced errors. In particular, imperfect instrument performance will have a detrimental impact on retrieval accuracy. The spectrometers need to be accurately calibrated with respect to spectral and radiometric performance and with respect to the instrument spectral response function. Erroneous calibration or in-orbit degradation of the instrument will map into retrieval errors. Further, G3E's mission concept requires that the four spectrometers observe the same ground scene since information on particle scattering and gas absorption is simultaneously retrieved from all spectral bands. Therefore, deficiencies in the optical alignment or in the characterization of the spectrometers' spatial response can have a detrimental impact on retrieval quality largely depending on scene heterogeneity. Further errors might be caused by erroneous input parameters to the retrieval algorithm such as meteorological and topographical input driving the calculation of surface pressure which is assumed accurately known by our retrieval concept. Likewise, spectroscopic parameters driving spectroscopic line shape models must be known with high accuracy to avoid erroneous fitting of absorption lines causing spurious correlations among interfering absorbers (e.g. Checa-Garcia et al., 2015). GOSAT $\mathrm{XCO}_{2}$ and $\mathrm{XCH}_{4}$ retrievals have shown that an overall accuracy in the subpercent range is achievable from LEO given proper instrument characterization, high-quality meteorological and topographic input, and careful assessment of the spectroscopic requirements (e.g. Dils et al., 2014).

Overall, the G3E mission and instrument concept is a candidate for making remote sensing of column-average greenhouse gas concentrations a routine tool in a continental-scale observation system that aims at monitoring greenhouse gas surface fluxes (Ciais et al., 2014). G3E's focus on greenhouse gases would complement current and upcoming satellite missions that target meteorological and air-quality related variables observable from GEO. Future work will focus on further refining mitigation strategies for aerosol- and cirrus-induced retrieval errors, on investigating sources of error other than addressed here, and on assessing the full potential of synergies with MTG. Beside using MTG-derived atmospheric scattering parameters for G3E's screening and retrieval procedures, MTG will provide concentration fields of pollutants such as $\mathrm{NO}_{2}$ which could be combined with $\mathrm{G} 3 \mathrm{E}$ 's $\mathrm{XCO}_{2}$ soundings to constrain anthropogenic sources. MTG will further dispose of the IRS infrared sounder whose thermal infrared emission soundings could be combined with G3E's solar backscatter measurements to derive vertical profile information on $\mathrm{CO}$ and to disentangle advected midtropospheric air masses from boundary layer emission processes. While Europe is G3E's primary focus region for which performance is tuned, the seasonally variable daytime conditions in Europe leave operation margins for observing other focus regions when Europe is dark. We will investigate to what extent central Africa, eastern tropical South America or Asia can be made into focus regions.

Acknowledgements. This work has been supported by Bundesministerium für Wirtschaft und Technologie, Germany, through Deutsches Zentrum für Luft- und Raumfahrt e.V. (DLR) contract 50EE1035. A. Butz is supported by Deutsche Forschungsgemeinschaft (DFG) through the Emmy-Noether program, grant BU2599/1-1 (RemoteC). We acknowledge further support by Deutsche Forschungsgemeinschaft and Open Access Publishing Fund of Karlsruhe Institute of Technology. The cirrus cloud model is a courtesy of the Royal Netherlands Meteorological Institute (KNMI) through Wouter Knap. ECHAM5-HAM model output is provided by Gerrit de Leeuw, Finnish Meteorological Institute (FMI). MODIS LAND data are distributed by the Land Processes Distributed Active Archive Center (LP DAAC), located at the US Geological Survey (USGS) Earth Resources Observation and Science Center (EROS) http://LPDAAC.usgs.gov. MODIS Atmosphere data are distributed through http://modis-atmos.gsfc.nasa.gov/index.html. We thank the ICARE Data and Services Center (http://www.icare.univ-lille1.fr) for providing access and assistance to the CALIOP data used in this study. TM4 modeled $\mathrm{CH}_{4}$ concentration fields have been made available through Jan Fokke Meirink, Royal Netherlands Meteorological Institute (KNMI). $\mathrm{CO}_{2}$ emissions shown in Fig. 1 are extracted from the ODIAC database by courtesy of Tom Oda, NASA Goddard Space Flight Center. We thank William Lahoz, Frank Hase, Stanley Sander, and Annmarie Eldering for stimulating discussions.

The article processing charges for this open-access publication were covered by a Research Centre of the Helmholtz Association.

Edited by: A. Lambert

\section{References}

Basu, S., Krol, M., Butz, A., Clerbaux, C., Sawa, Y., Machida, T., Matsueda, H., Frankenberg, C., Hasekamp, O. P., and Aben, I.: The seasonal variation of the $\mathrm{CO}_{2}$ flux over Tropical Asia estimated from GOSAT, CONTRAIL, and IASI, Geophys. Res. Lett., 41, 1809-1815, doi:10.1002/2013GL059105, 2014.

Bergamaschi, P., Frankenberg, C., Meirink, J. F., Krol, M., Dentener, F., Wagner, T., Platt, U., Kaplan, J. O., Körner, S., Heimann, M., Dlugokencky, E. J., and Goede, A.: Satellite chartography of atmospheric methane from SCIAMACHY on board ENVISAT: 2. Evaluation based on inverse model simulations, J Geophys. Res., 112, 2304, doi:10.1029/2006JD007268, 2007.

Bergamaschi, P., Frankenberg, C., Meirink, J. F., Krol, M., Villani, M. G., Houweling, S., Dentener, F., Dlugokencky, E. J., Miller, J. B., Gatti, L. V., Engel, A., and Levin, I.: Inverse modeling of global and regional $\mathrm{CH}_{4}$ emissions using SCIAMACHY satellite retrievals, J. Geophys. Res., 114, 22301, doi:10.1029/2009JD012287, 2009. 
Bovensmann, H., Burrows, J. P., Buchwitz, M., Frerick, J., Noël, S., Rozanov, V. V., Chance, K. V., and Goede, A. P. H.: SCIAMACHY: Mission Objectives and Measurement Modes, J. Atmos. Sci., 56, 127-150, doi:10.1175/15200469(1999)056<0127:SMOAMM>2.0.CO;2, 1999.

Bovensmann, H., Noel, S., Monks, P., Goede, A., and Burrows, J.: The geostationary scanning imaging absorption spectrometer (GeoSCIA) mission: requirements and capabilities, Adv. Space Res., 29, 1849-1859, doi:10.1016/S0273-1177(02)001047, 2002.

Bovensmann, H., Eichmann, K. U., Noël, S., Flaud, J. M., Orphal, J., Monks, P. S., Corlett, G. K., Goede, A. P. H., von Clarmann, T., Steck, T., Rozanov, V., and Burrows, J. B.: The geostationary scanning imaging absorption spectrometer (GeoSCIA) as part of the geostationary tropospheric pollution explorer (GeoTROPE) mission: requirements, concepts and capabilities, Adv. Space Res., 34, 694-699, doi:10.1016/j.asr.2003.08.068, 2004.

Bovensmann, H., Buchwitz, M., Burrows, J. P., Reuter, M., Krings, T., Gerilowski, K., Schneising, O., Heymann, J., Tretner, A., and Erzinger, J.: A remote sensing technique for global monitoring of power plant $\mathrm{CO}_{2}$ emissions from space and related applications, Atmos. Meas. Tech., 3, 781-811, doi:10.5194/amt-3-781-2010, 2010.

Buchwitz, M., Reuter, M., Bovensmann, H., Pillai, D., Heymann, J., Schneising, O., Rozanov, V., Krings, T., Burrows, J. P., Boesch, H., Gerbig, C., Meijer, Y., and Löscher, A.: Carbon Monitoring Satellite (CarbonSat): assessment of atmospheric $\mathrm{CO}_{2}$ and $\mathrm{CH}_{4}$ retrieval errors by error parameterization, Atmos. Meas. Tech., 6, 3477-3500, doi:10.5194/amt-6-3477-2013, 2013.

Burrows, J. P., Hölzle, E., Goede, A. P. H., Visser, H., and Fricke, W.: SCIAMACHY - scanning imaging absorption spectrometer for atmospheric chartography, Acta Astronaut., 35, 445-451, doi:10.1016/0094-5765(94)00278-T, 1995.

Butz, A., Hasekamp, O. P., Frankenberg, C., and Aben, I.: Retrievals of atmospheric $\mathrm{CO}_{2}$ from simulated space-borne measurements of backscattered near-infrared sunlight: accounting for aerosol effects, Appl. Optics, 48, 3322, doi:10.1364/AO.48.003322, 2009.

Butz, A., Hasekamp, O. P., Frankenberg, C., Vidot, J., and Aben, I.: $\mathrm{CH}_{4}$ retrievals from space-based solar backscatter measurements: performance evaluation against simulated aerosol and cirrus loaded scenes, J. Geophys. Res., 115, 24302, doi:10.1029/2010JD014514, 2010.

Butz, A., Guerlet, S., Hasekamp, O., Schepers, D., Galli, A., Aben, I., Frankenberg, C., Hartmann, J.-M., Tran, H., Kuze, A., Keppel-Aleks, G., Toon, G., Wunch, D., Wennberg, P., Deutscher, N., Griffith, D., Macatangay, R., Messerschmidt, J., Notholt, J., and Warneke, T.: Toward accurate $\mathrm{CO}_{2}$ and $\mathrm{CH}_{4}$ observations from GOSAT, Geophys. Res. Lett., 38, L14812, doi:10.1029/2011GL047888, 2011.

Butz, A., Galli, A., Hasekamp, O., Landgraf, J., Tol, P., and Aben, I.: TROPOMI aboard Sentinel-5 precursor: prospective performance of $\mathrm{CH}_{4}$ retrievals for aerosol and cirrus loaded atmospheres, Remote Sens. Environ., 120, 267-276, doi:10.1016/j.rse.2011.05.030, 2012.

Butz, A., Guerlet, S., Hasekamp, O. P., Kuze, A., and Suto, H.: Using ocean-glint scattered sunlight as a diagnostic tool for satel- lite remote sensing of greenhouse gases, Atmos. Meas. Tech., 6, 2509-2520, doi:10.5194/amt-6-2509-2013, 2013.

Checa-Garcia, R., Landgraf, J., Galli, A., Hase, F., Velazco, V. A., Tran, H., Boudon, V., Alkemade, F., and Butz, A.: Mapping spectroscopic uncertainties into prospective methane retrieval errors from Sentinel-5 and its precursor, Atmos. Meas. Tech., 8, 36173629, doi:10.5194/amt-8-3617-2015, 2015.

Chevallier, F., Bréon, F.-M., and Rayner, P. J.: Contribution of the Orbiting Carbon Observatory to the estimation of $\mathrm{CO}_{2}$ sources and sinks: theoretical study in a variational data assimilation framework, J. Geophys. Res., 112, 9307, doi:10.1029/2006JD007375, 2007.

Ciais, P., Dolman, A. J., Bombelli, A., Duren, R., Peregon, A., Rayner, P. J., Miller, C., Gobron, N., Kinderman, G., Marland, G., Gruber, N., Chevallier, F., Andres, R. J., Balsamo, G., Bopp, L., Bréon, F.-M., Broquet, G., Dargaville, R., Battin, T. J., Borges, A., Bovensmann, H., Buchwitz, M., Butler, J., Canadell, J. G., Cook, R. B., DeFries, R., Engelen, R., Gurney, K. R., Heinze, C., Heimann, M., Held, A., Henry, M., Law, B., Luyssaert, S., Miller, J., Moriyama, T., Moulin, C., Myneni, R. B., Nussli, C., Obersteiner, M., Ojima, D., Pan, Y., Paris, J.-D., Piao, S. L., Poulter, B., Plummer, S., Quegan, S., Raymond, P., Reichstein, M., Rivier, L., Sabine, C., Schimel, D., Tarasova, O., Valentini, R., Wang, R., van der Werf, G., Wickland, D., Williams, M., and Zehner, C.: Current systematic carbon-cycle observations and the need for implementing a policy-relevant carbon observing system, Biogeosciences, 11, 3547-3602, doi:10.5194/bg-113547-2014, 2014.

Crisp, D., Atlas, R. M., Bréon, F.-M., Brown, L. R., Burrows, J. P., Ciais, P., Connor, B. J., Doney, S. C., Fung, I. Y., Jacob, D. J., Miller, C. E., O'Brien, D., Pawson, S., Randerson, J. T., Rayner, P., Salawitch, R. J., Sander, S. P., Sen, B., Stephens, G. L., Tans, P. P., Toon, G. C., Wennberg, P. O., Wofsy, S. C., Yung, Y. L., Kuang, Z., Chudasama, B., Sprague, G., Weiss, B., Pollock, R., Kenyon, D., and Schroll, S.: The Orbiting Carbon Observatory (OCO) mission, Adv. Space Res., 34, 700-709, doi:10.1016/j.asr.2003.08.062, 2004.

Dils, B., Buchwitz, M., Reuter, M., Schneising, O., Boesch, H., Parker, R., Guerlet, S., Aben, I., Blumenstock, T., Burrows, J. P., Butz, A., Deutscher, N. M., Frankenberg, C., Hase, F., Hasekamp, O. P., Heymann, J., De Mazière, M., Notholt, J., Sussmann, R., Warneke, T., Griffith, D., Sherlock, V., and Wunch, D.: The Greenhouse Gas Climate Change Initiative (GHG-CCI): comparative validation of GHG-CCI SCIAMACHY/ENVISAT and TANSO-FTS/GOSAT $\mathrm{CO} 2$ and $\mathrm{CH} 4$ retrieval algorithm products with measurements from the TCCON, Atmos. Meas. Tech., 7, 1723-1744, doi:10.5194/amt-7-1723-2014, 2014.

Frankenberg, C., Meirink, J. F., van Weele, M., Platt, U., and Wagner, T.: Assessing methane emissions from global space-borne observations, Science, 308, 1010-1014, doi:10.1126/science.1106644, 2005.

Frankenberg, C., Butz, A., and Toon, G. C.: Disentangling chlorophyll fluorescence from atmospheric scattering effects in $\mathrm{O}_{2} \mathrm{~A}-$ band spectra of reflected sun-light, Geophys. Res. Lett., 38, 3801, doi:10.1029/2010GL045896, 2011.

Gottwald, M. and Bovensmann, H. (Eds.): SCIAMACHY - Exploring the Changing Earth's Atmosphere, Springer, Heidelberg, Dordrecht, London, New York, doi:10.1007/978-90-481-9896-2, 2011. 
Guerlet, S., Butz, A., Schepers, D., Basu, S., Hasekamp, O. P., Kuze, A., Yokota, T., Blavier, J.-F., Deutscher, N. M., Griffith, D. W. T., Hase, F., Kyro, E., Morino, I., Sherlock, V., Sussmann, R., Galli, A., and Aben, I.: Impact of aerosol and thin cirrus on retrieving and validating $\mathrm{XCO}_{2}$ from GOSAT shortwave infrared measurements, J. Geophys. Res., 118, 4887-4905, doi:10.1002/jgrd.50332, 2013a.

Guerlet, S., Basu, S., Butz, A., Krol, M., Hahne, P., Houweling, S., Hasekamp, O. P., and Aben, I.: Reduced carbon uptake during the 2010 Northern Hemisphere summer from GOSAT, Geophys. Res. Lett., 40, 2378-2383, doi:10.1002/grl.50402, 2013 b.

Hess, M.: Scattering matrices of imperfect hexagonal ice crystals, J. Quant. Spectrosc. Ra., 60, 301-308, doi:10.1016/S00224073(98)00007-7, 1998

Hess, M. and Wiegner, M.: COP: a data library of optical properties of hexagonal ice crystals, Appl. Optics, 33, 7740-7746, 1994.

Hungershoefer, K., Breon, F.-M., Peylin, P., Chevallier, F., Rayner, P., Klonecki, A., Houweling, S., and Marshall, J.: Evaluation of various observing systems for the global monitoring of CO2 surface fluxes, Atmos. Chem. Phys., 10, 10503-10520, doi:10.5194/acp-10-10503-2010, 2010.

Ingmann, P., Veihelmann, B., Langen, J., Lamarre, D., Stark, H., and Courrèges-Lacoste, G. B.: Requirements for the GMES Atmosphere Service and ESA's implementation concept: Sentinels-4/-5 and -5p, Remote Sens. Environ., 120, 58-69, doi:10.1016/j.rse.2012.01.023, 2012.

Inness, A., Blechschmidt, A.-M., Bouarar, I., Chabrillat, S., Crepulja, M., Engelen, R. J., Eskes, H., Flemming, J., Gaudel, A., Hendrick, F., Huijnen, V., Jones, L., Kapsomenakis, J., Katragkou, E., Keppens, A., Langerock, B., de Mazière, M., Melas, D., Parrington, M., Peuch, V. H., Razinger, M., Richter, A., Schultz, M. G., Suttie, M., Thouret, V., Vrekoussis, M., Wagner, A., and Zerefos, C.: Data assimilation of satelliteretrieved ozone, carbon monoxide and nitrogen dioxide with ECMWF's Composition-IFS, Atmos. Chem. Phys., 15, 52755303, doi:10.5194/acp-15-5275-2015, 2015.

Kort, E. A., Frankenberg, C., Miller, C. E., and Oda, T.: Space-based observations of megacity carbon dioxide, Geophys. Res. Lett., 39, 17806, doi:10.1029/2012GL052738, 2012.

Kort, E. A., Frankenberg, C., Costigan, K. R., Lindenmaier, R., Dubey, M. K., and Wunch, D.: Four corners: the largest US methane anomaly viewed from space, Geophys. Res. Lett., 41, 6898-6903, doi:10.1002/2014GL061503, 2014.

Kuze, A., Suto, H., Nakajima, M., and Hamazaki, T.: Thermal and near infrared sensor for carbon observation Fouriertransform spectrometer on the Greenhouse Gases Observing Satellite for greenhouse gases monitoring, Appl. Optics, 48, 6716, doi:10.1364/AO.48.006716, 2009.

Meirink, J. F., Eskes, H. J., and Goede, A. P. H.: Sensitivity analysis of methane emissions derived from SCIAMACHY observations through inverse modelling, Atmos. Chem. Phys., 6, 1275-1292, doi:10.5194/acp-6-1275-2006, 2006.

Miller, C. E., Crisp, D., DeCola, P. L., Olsen, S. C., Randerson, J. T., Michalak, A. M., Alkhaled, A., Rayner, P., Jacob, D. J., Suntharalingam, P., Jones, D. B. A., Denning, A. S., Nicholls, M. E., Doney, S. C., Pawson, S., Bösch, H., Connor, B. J., Fung, I. Y., O'Brien, D., Salawitch, R. J., Sander, S. P., Sen, B., Tans, P., Toon, G. C., Wennberg, P. O., Wofsy, S. C., Yung, Y. L., and Law, R. M.: Precision requirements for space-based $\mathrm{X}_{\mathrm{CO}_{2}}$ data, J. Geophys. Res., 112, 10314, doi:10.1029/2006JD007659, 2007.

Oda, T. and Maksyutov, S.: A very high-resolution $(1 \mathrm{~km} \times 1 \mathrm{~km})$ global fossil fuel $\mathrm{CO}_{2}$ emission inventory derived using a point source database and satellite observations of nighttime lights, Atmos. Chem. Phys., 11, 543-556, doi:10.5194/acp-11-543-2011, 2011.

O’Dell, C. W., Connor, B., Bösch, H., O’Brien, D., Frankenberg, C., Castano, R., Christi, M., Eldering, D., Fisher, B., Gunson, M., McDuffie, J., Miller, C. E., Natraj, V., Oyafuso, F., Polonsky, I., Smyth, M., Taylor, T., Toon, G. C., Wennberg, P. O., and Wunch, D.: The ACOS $\mathrm{CO}_{2}$ retrieval algorithm - Part 1: Description and validation against synthetic observations, Atmos. Meas. Tech., 5, 99-121, doi:10.5194/amt-5-99-2012, 2012.

Oshchepkov, S., Bril, A., and Yokota, T.: PPDF-based method to account for atmospheric light scattering in observations of carbon dioxide from space, J. Geophys. Res., 113, 23210, doi:10.1029/2008JD010061, 2008.

Parazoo, N. C., Bowman, K., Frankenberg, C., Lee, J.-E., Fisher, J. B., Worden, J., Jones, D. B. A., Berry, J., Collatz, G. J., Baker, I. T., Jung, M., Liu, J., Osterman, G., O’Dell, C., Sparks, A., Butz, A., Guerlet, S., Yoshida, Y., Chen, H., and Gerbig, C.: Interpreting seasonal changes in the carbon balance of southern Amazonia using measurements of $\mathrm{XCO}_{2}$ and chlorophyll fluorescence from GOSAT, Geophys. Res. Lett., 40, 2829 2833, doi:10.1002/grl.50452, 2013.

Peters, W., Jacobson, A. R., Sweeney, C., Andrews, A. E., Conway, T. J., Masarie, K., Miller, J. B., Bruhwiler, L. M. P., Petron, G., Hirsch, A. I., Worthy, D. E. J., van der Werf, G. R., Randerson, J. T., Wennberg, P. O., Krol, M. C., and Tans, P. P.: An atmospheric perspective on North American carbon dioxide exchange: CarbonTracker, P. Natl. Acad. Sci. USA, 104, 1892518930, 2007.

Phillips, D.: A technique for the numerical solution of certain integral equations of first kind, J. ACM, 9, 84-97, 1962.

Polonsky, I. N., O’Brien, D. M., Kumer, J. B., O’Dell, C. W., and the geoCARB Team: Performance of a geostationary mission, geoCARB, to measure $\mathrm{CO}_{2}, \mathrm{CH}_{4}$ and $\mathrm{CO}$ column-averaged concentrations, Atmos. Meas. Tech., 7, 959-981, doi:10.5194/amt7-959-2014, 2014.

Rayner, P. J., and O'Brien, D. M.: The utility of remotely sensed $\mathrm{CO}_{2}$ concentration data in surface source inversions, Geophys. Res. Lett., 28, 175-178, doi:10.1029/2000GL011912, 2001.

Rayner, P. J., Utembe, S. R., and Crowell, S.: Constraining regional greenhouse gas emissions using geostationary concentration measurements: a theoretical study, Atmos. Meas. Tech., 7, 3285-3293, doi:10.5194/amt-7-3285-2014, 2014.

Reuter, M., Bovensmann, H., Buchwitz, M., Burrows, J. P., Connor, B. J., Deutscher, N. M., Griffith, D. W. T., Heymann, J., Keppel-Aleks, G., Messerschmidt, J., Notholt, J., Petri, C., Robinson, J., Schneising, O., Sherlock, V., Velazco, V., Warneke, T., Wennberg, P. O., and Wunch, D.: Retrieval of atmospheric $\mathrm{CO}_{2}$ with enhanced accuracy and precision from SCIAMACHY: validation with FTS measurements and comparison with model results, J. Geophys. Res., 116, 04301, doi:10.1029/2010JD015047, 2011.

Reuter, M., Buchwitz, M., Hilboll, A., Richter, A., Schneising, O., Hilker, M., Heymann, J., Bovensmann, H., and Burrows, J. P.: Decreasing emissions of $\mathrm{NO}_{x}$ relative to $\mathrm{CO}_{2}$ in East Asia 
inferred from satellite observations, Nat. Geosci., 7, 792-795, doi:10.1038/ngeo2257, 2014a.

Reuter, M., Buchwitz, M., Hilker, M., Heymann, J., Schneising, O., Pillai, D., Bovensmann, H., Burrows, J. P., Bösch, H., Parker, R., Butz, A., Hasekamp, O., O’Dell, C. W., Yoshida, Y., Gerbig, C., Nehrkorn, T., Deutscher, N. M., Warneke, T., Notholt, J., Hase, F., Kivi, R., Sussmann, R., Machida, T., Matsueda, H., and Sawa, Y.: Satellite-inferred European carbon sink larger than expected, Atmos. Chem. Phys., 14, 13739-13753, doi:10.5194/acp-14-13739-2014, 2014b.

Rodgers, C. D.: Inverse Methods for Atmospheric Sounding: Theory and Practice, World Scientific, River Edge, NJ, USA, 256 pp., 2000.

Ross, A. N., Wooster, M. J., Boesch, H., and Parker, R.: First satellite measurements of carbon dioxide and methane emission ratios in wildfire plumes, Geophys. Res. Lett., 40, 4098-4102, doi:10.1002/grl.50733, 2013.

Schepers, D., Guerlet, S., Butz, A., Landgraf, J., Frankenberg, C., Hasekamp, O., Blavier, J.-F., Deutscher, N. M., Griffith, D. W. T., Hase, F., Kyro, E., Morino, I., Sherlock, V., Sussmann, R., and Aben, I.: Methane retrievals from Greenhouse Gases Observing Satellite (GOSAT) shortwave infrared measurements: performance comparison of proxy and physics retrieval algorithms, J. Geophys. Res., 117, D10307, doi:10.1029/2012JD017549, 2012.

Schneising, O., Heymann, J., Buchwitz, M., Reuter, M., Bovensmann, H., and Burrows, J. P.: Anthropogenic carbon dioxide source areas observed from space: assessment of regional enhancements and trends, Atmos. Chem. Phys., 13, 2445-2454, doi:10.5194/acp-13-2445-2013, 2013.

Stier, P., Feichter, J., Kinne, S., Kloster, S., Vignati, E., Wilson, J., Ganzeveld, L., Tegen, I., Werner, M., Balkanski, Y., Schulz, M., Boucher, O., Minikin, A., and Petzold, A.: The aerosol-climate model ECHAM5-HAM, Atmos. Chem. Phys., 5, 1125-1156, doi:10.5194/acp-5-1125-2005, 2005.
Tikhonov, A.: On the solution of incorrectly stated problems and method of regularization, Dokl. Akad. Nauk. SSSR+, 151, 501504, 1963.

Veefkind, J., Aben, I., McMullan, K., Förster, H., de Vries, J., Otter, G., Claas, J., Eskes, H., de Haan, J., Kleipool, Q., van Weele, M., Hasekamp, O., Hoogeveen, R., Landgraf, J., Snel, R., Tol, P., Ingmann, P., Voors, R., Kruizinga, B., Vink, R., Visser, H., and Levelt, P.: TROPOMI on the ESA Sentinel-5 precursor: a GMES mission for global observations of the atmospheric composition for climate, air quality and ozone layer applications, the Sentinel missions - new opportunities for science, Remote Sens. Environ., 120, 70-83, doi:10.1016/j.rse.2011.09.027, 2012.

Velazco, V. A., Buchwitz, M., Bovensmann, H., Reuter, M., Schneising, O., Heymann, J., Krings, T., Gerilowski, K., and Burrows, J. P.: Towards space based verification of $\mathrm{CO}_{2}$ emissions from strong localized sources: fossil fuel power plant emissions as seen by a CarbonSat constellation, Atmos. Meas. Tech., 4, 2809-2822, doi:10.5194/amt-4-2809-2011, 2011.

Vidot, J., Landgraf, J., Hasekamp, O., Butz, A., Galli, A., Tol, P., and Aben, I.: Carbon monoxide from shortwave infrared reflectance measurements: a new retrieval approach for clear sky and partially cloudy atmospheres, Remote Sens. Environ., 120, 255-266, doi:10.1016/j.rse.2011.09.032, 2012.

Winker, D. M., Hunt, W. H., and McGill, M. J.: Initial performance assessment of CALIOP, Geophys. Res. Lett., 34, 19803, doi:10.1029/2007GL030135, 2007.

Wunch, D., Wennberg, P. O., Toon, G. C., Keppel-Aleks, G., and Yavin, Y. G.: Emissions of greenhouse gases from a North American megacity, Geophys. Res. Lett., 36, 15810, doi:10.1029/2009GL039825, 2009. 